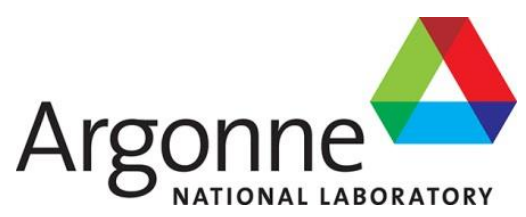

ANL/NSE-21/30

\title{
Assessment of MOOSE-Based Tools for Calculating Radial Core Expansion
}

Nuclear Science and Engineering Division 


\section{About Argonne National Laboratory}

Argonne is a U.S. Department of Energy laboratory managed by UChicago Argonne, LLC under contract DE-AC02-06CH11357. The Laboratory's main facility is outside Chicago, at 9700 South Cass Avenue, Argonne, Illinois 60439. For information about Argonne and its pioneering science and technology programs, see www.anl.gov.

\section{DOCUMENT AVAILABILITY}

Online Access: U.S. Department of Energy (DOE) reports produced after 1991 and a growing number of pre-1991 documents are available free at OSTI.GOV (http://www.osti.gov/), a service of the US Dept. of Energy's Office of Scientific and Technical Information.

Reports not in digital format may be purchased by the public from the National Technical Information Service (NTIS):

U.S. Department of Commerce

National Technical Information Service

5301 Shawnee Rd

Alexandria, VA 22312

www.ntis.gov

Phone: (800) 553-NTIS (6847) or (703) 605-6000

Fax: (703) 605-6900

Email:orders@ntis.gov

Reports not in digital format are available to DOE and DOE contractors from the Office of Scientific and Technical Information (OSTI):

U.S. Department of Energy

Office of Scientific and Technical Information

P.O. Box 62

Oak Ridge, TN 37831-0062

www.osti.gov

Phone: (865) 576-8401

Fax: (865) 576-5728

Email: reports@osti.gov

\section{Disclaimer}

This report was prepared as an account of work sponsored by an agency of the United States Government. Neither the United States Government nor any agency thereof, nor UChicago Argonne, LLC, nor any of their employees or officers, makes any warranty, express or implied, or assumes any legal liability or responsibility for the accuracy, completeness, or usefulness of any information, apparatus, product, or process disclosed, or represents that its use would not infringe privately owned rights. Reference herein to any specific commercial product, process, or service by trade name, trademark, manufacturer, or otherwise, does not necessarily constitute or imply its endorsement, recommendation, or favoring by the United States Government or any agency thereof. The views and opinions of document authors expressed herein do not necessarily state or reflect those of the United States Government or any agency thereof, Argonne National Laboratory, or UChicago Argonne, LLC. 
ANL/NSE-21/30

\section{Assessment of MOOSE-Based Tools for Calculating Radial Core Expansion}

prepared by

Nicholas Wozniak ${ }^{1}$, Emily Shemon ${ }^{2}$, James Grudzinski ${ }^{1}$, and Benjamin Spencer ${ }^{3}$

${ }^{1}$ Experimental Operations and Facilities Division, Argonne National Laboratory

${ }^{2}$ Nuclear Science and Engineering Division, Argonne National Laboratory

${ }^{3}$ Idaho National Laboratory

July 12,2021 


\begin{abstract}
Radial core expansion in liquid-metal cooled fast reactor systems is a well-known phenomenon that produces strong reactivity feedback effects. An inherently safe reactor design takes advantage of negative reactivity feedback in accident scenarios by utilizing a core restraint system which produces a bowed shape that allows for radial expansion of the fuel regions. Detailed modeling and simulation of radial core expansion itself as well as subsequent reactivity feedback is a challenging task involving contact of many fuel assembly elements and physics feedback from neutronics, thermal hydraulics, and thermal mechanical response. A variety of physics codes have been developed to model aspects of radial core expansion but in general invoke geometrical or physics approximations [1]. No code system currently exists which tightly and robustly couples these physics with enough detail to fully resolve the complex radial core expansion reactivity feedback effects. The future availability of such a code system is of vital importance to fully understanding the reactivity feedback effects that occur due to radial expansion, and consequently to optimizing the design of the core restraint system. A high-fidelity code will also be used to benchmark existing lower fidelity, faster running models to understand their benefits, limitations, and range of applications. A code development path using MOOSE-based [2] tools is proposed in order to leverage the detailed geometry capabilities and natural tight coupling and robustness of MOOSE-based applications for modeling this complex phenomena.

While simulation of the full phenomenon involves several physics, an assessment has been initiated on the capabilities and readiness of the currently available Tensor Mechanics module within MOOSE for calculation of the structural mechanical responses which occur within the reactor core. This report focuses on modeling the force-deformation response which mimics the physics of a duct contact deformation, as well as differential thermal expansion which produces a thermal bowed shaped for the fuel assemblies in a core. Simple examples were initially performed such as simple supported beam bending under load. The complexity of examples was progressively increased to better mimic the duct behavior by including a differential thermal example and inclusion of hexagonal cross-sections in the geometry. Further assessment of the structural mechanical response simulation capability is still required for modeling duct contact interactions and irradiation creep and swelling.

Companion thermal hydraulic and neutronics assessments will also be required; these activities are planned for future years. Finally, integration of the multiple physics components through MOOSE is required to predict the radial core expansion and subsequent feedback effects.
\end{abstract}




\section{Contents}

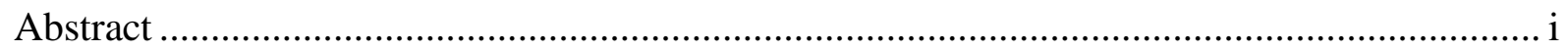

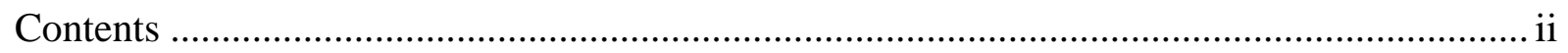

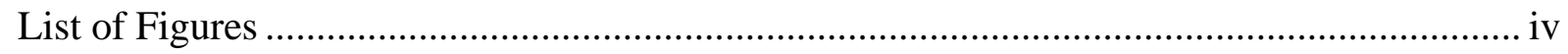

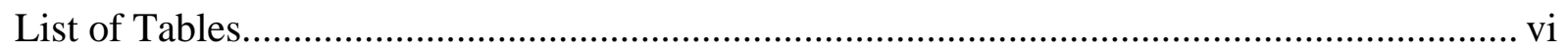

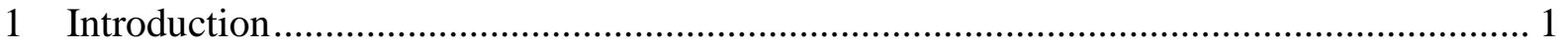

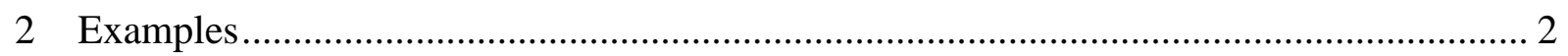

2.1 Example 1 - Concentrated Load on Square Beam........................................................... 3

2.1.1. Example 1A - Solid Section ...................................................................... 4

2.1.2. Example 1B - Hollow Section ...................................................................... 6

2.2 Example 2 - Distributed Load on Square Beam ........................................................ 8

2.2.1. Example 2A - Solid Section ........................................................................ 9

2.2.2. Example 2B - Hollow Section .................................................................... 11

2.3 Example 3 - Distributed Load on Hexagonal Duct .......................................................... 13

2.4 Example 4 - Concentrated Load on Cantilever Square Beam ........................................ 16

2.5 Example 5 (IAEA Verification Problem 1) ..................................................................... 18

2.6 Example 6 (IAEA Verification Problem 3A) ................................................................ 20

2.7 Comparison of Example Results ................................................................................ 23

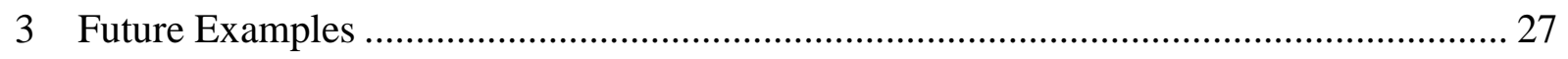

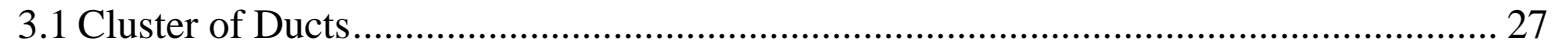

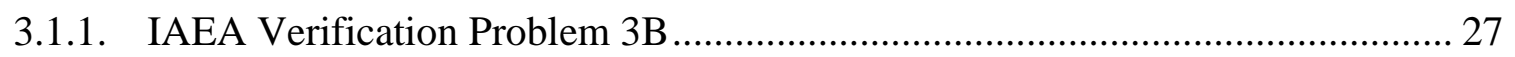

3.2 Core Symmetric Sector …………........................................................................... 28

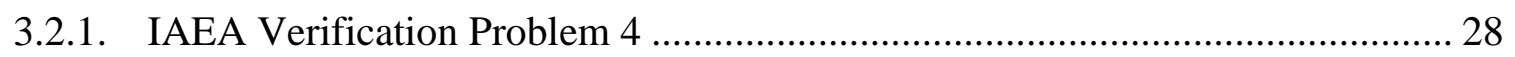

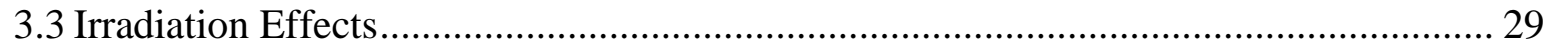

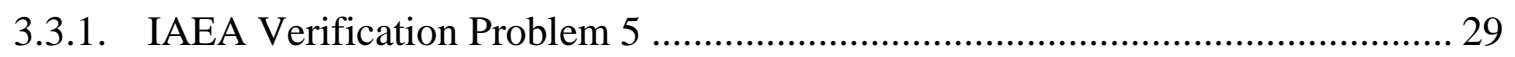

3.3.2. IAEA Verification Problem 6 ……………….................................................. 30

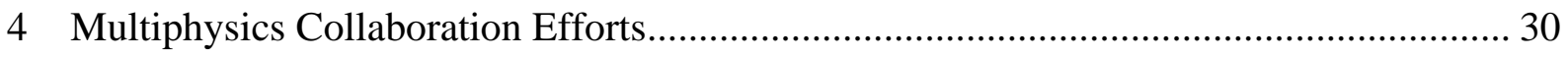

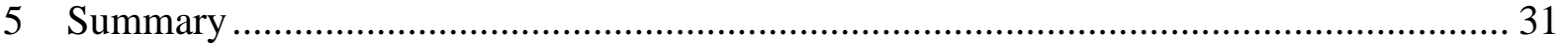




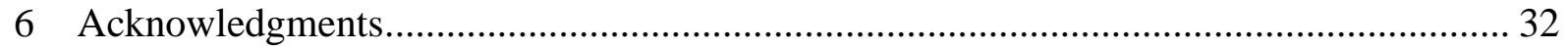

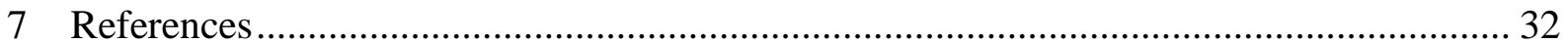




\section{List of Figures}

Figure 1.1. Tensors required to fully describe a mechanics material (adopted from [2])......... 1

Figure 2.1. Simply supported beam with a concentrated force, $\mathrm{P}$, at the midspan, L/2.......... 3

Figure 2.2. Solid beam mesh for Example 1A ................................................................... 4

Figure 2.3. Deformation (in.) from MOOSE calculation for Example 1A for the

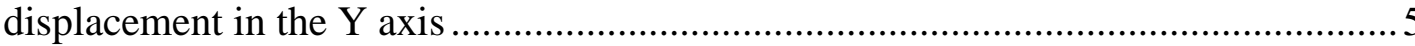

Figure 2.4. Displacement versus length from MOOSE deflection calculations with the closed form solution, SAP2000 results, and Ansys results...................................... 6

Figure 2.5. Hollow beam mesh for Example 1B .......................................................... 7

Figure 2.6. Deformation (in.) from MOOSE calculation for Example 1B for the

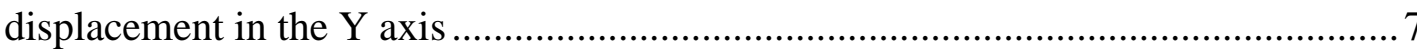

Figure 2.7. Displacement versus length from MOOSE deflection calculations with the closed form solution, SAP2000 results, and Ansys results................................. 8

Figure 2.8. Simply supported beam with a uniformly distributed load, w, along the span, L...9

Figure 2.9. Deformation (in.) from MOOSE calculation for Example 2A for the displacement in the $\mathrm{Y}$ axis 10

Figure 2.10. Displacement versus length from MOOSE deflection calculations with the closed form solution, SAP2000 results, and Ansys results

Figure 2.11. Deformation (in.) from MOOSE calculation for Example 2B for the displacement in the $\mathrm{Y}$ axis

Figure 2.12. Displacement versus length from MOOSE deflection calculations with the closed form solution, SAP2000 results, and Ansys results. 13

Figure 2.13. Cross section for hex duct model ............................................................. 14

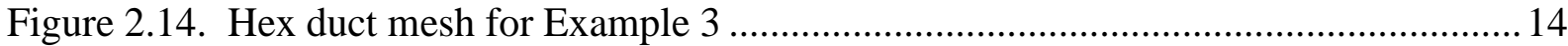

Figure 2.15. Deformation (in.) from MOOSE calculation for Example 3 for the displacement in the $\mathrm{Y}$ axis

Figure 2.16. Displacement versus length from MOOSE deflection calculations with the closed form solution, SAP2000 results, and Ansys results................................... 16

Figure 2.17. Cantilever beam with a concentrated force, $\mathrm{P}$, at the free end ......................... 17

Figure 2.18. Deformation (in.) from MOOSE calculation for Example 4 for the displacement in the $\mathrm{Y}$ axis

Figure 2.19. Displacement versus length from MOOSE deflection calculations with the closed form solution, SAP2000 results, and Ansys results 
Figure 2.20. Schematic showing the thermal gradient developed axially along the core region of the duct, showing the temperature difference achieved along the corners directions.

Figure 2.21. Maximum corner temperatures at the top of the core region .......................... 19

Figure 2.22. Temperature gradient (left) in ${ }^{\circ} \mathrm{F}$, and the displacement (right)........................ 20

Figure 2.23. Model for IAEA VP3A of $60^{\circ}$ symmetric core region with a free boundary, represented by the red dashed line. The blue arrow indicates the direction of the thermal gradient induced bow for duct 1 (Adapted from [4] ( IAEA)......................2 21

Figure 2.24. MOOSE model of ducts 1, 3, 10, and 11 in IAEA VP3A. Shown are (left) the deformed mesh looking from the top of the ducts, and (right) the prescribed temperature field on duct 1 . The y-plane is used as a symmetry plane in this model.22

Figure 2.25. History of y-component of displacement at the top of the four ducts modeled in the process of incrementally applying the prescribed thermal gradient. The full thermal gradient is applied at time $=1.0$.

Figure 3.1. Model for IAEA VP3B of $120^{\circ}$ symmetric core region with a free boundary, represented by the red dashed line. The blue arrow indicates the direction of the thermal gradient induced bow for duct 1 (Adapted from [4] (C) IAEA)....................28

Figure 3.2. Model for IAEA VP4 of $30^{\circ}$ symmetric core region, represented by the red dashed line, with a core restraint ring at the TLP and ACLP. The blue arrows indicate the direction of the thermal gradient induced bow for ducts 42, 43, and 44 (Adapted from [4] (C) IAEA).

Figure 3.3. Core model showing the location where the neutron damage dose is active within the circle, for examples 5, 6, and 8A (Adopted from [4] (C IAEA). 


\section{List of Tables}

Table 2.1. Common parameters and material properties used for examples .......................... 2

Table 2.2. Comparison of maximum centerline deflection results between MOOSE, the

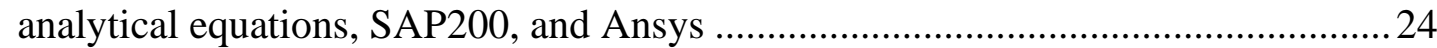

Table 2.3. Error percentage of maximum centerline deflection results between MOOSE, the

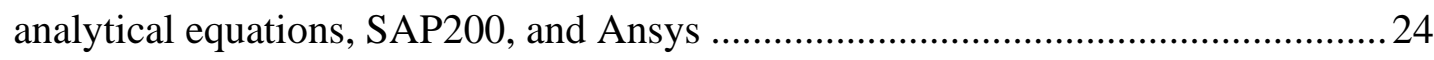

Table 2.4. Summary of the example problems for MOOSE assessment............................... 25 


\section{Introduction}

The Tensor Mechanics Module is a library of code modules based on MOOSE used in continuum mechanics simulations, which models the mechanical deformation and stresses of solids [2]. It can be used in pure mechanics simulations or in multiphysics simulations with other MOOSE modules such as heat transfer, phase field, contact, porous flow, and XFEM (the extended finite element method used to treat PDEs with discontinuities). The tensor mechanics system can be used to simulate both linear and finite strain mechanics, including elasticity and Cosserat elasticity, plasticity and micromechanics plasticity, creep, and damage due to cracking and property degradation. It supports both small and finite strain formulations. There are also multiple methods for calculating elastic stress, plastic stress, creep stress, and a combination of stress calculation methods.

The constitutive models in Tensor Mechanics are implemented in a modular fashion, with a standard set of models for the various calculations leading up to computing the current stress. Figure 1.1 shows the basic set of calculations required for stress calculation problems: the strain, constitutive/elasticity $\left(\mathrm{C}_{\mathrm{ijk}}\right)$, and stress tensors. In addition, the module allows for eigenstrains and extra stress definitions. Eigenstrains are defined as mechanical deformation not caused by external stresses such as thermal expansion or deformations due to dislocations. An extra stress is typically a residual stress. Multiple formulations for each of these computations are available, and can be used interchangeably, permitting a wide variety of combinations of calculation types.

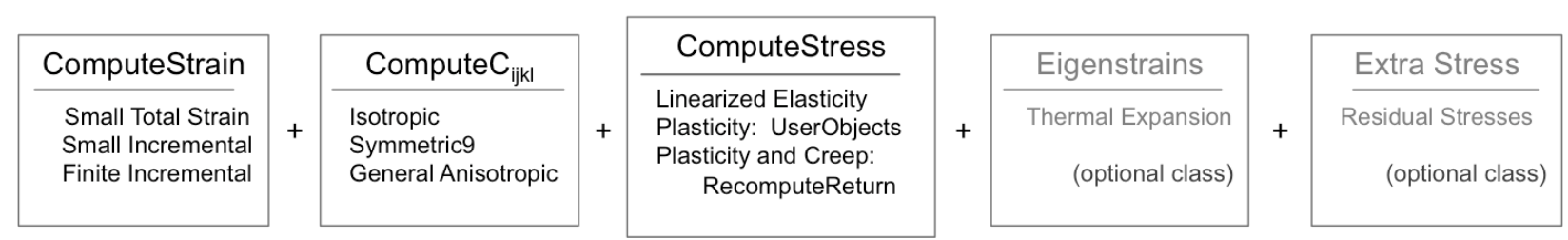

Figure 1.1. Tensors required to fully describe a mechanics material (adopted from [2]) 


\section{Examples}

Example problems were created to assess the capabilities of the Tensor Mechanics module in MOOSE to perform structural mechanics calculations. Simple examples were examined first, followed by additional examples with progressively increasing geometric and physics complexities. Examples were selected based on whether they have a closed-form solution to compare against, or a simulation which could be duplicated in other software for code-to-code comparison.

Some of the necessary structural mechanical physics responses which are required to estimate the reactivity feedback in a reactor core are:

- Deformation of the fuel assemblies,

- Contact forces at the load pads between assemblies, and

- Stresses induced within the assemblies (due to contact pressure) to calculate creep and swelling effects.

The current examples focused on correctly estimating the deformation response due to contact forces or differential thermal expansion. The examples were all performed with a basic beam description, made of a simple steel material. The parameters and material properties are listed in Table 2.1.

Table 2.1. Common parameters and material properties used for examples

\begin{tabular}{ccc}
\hline \hline Parameter & Description & Value \\
\hline L & Length of beam (in) & 120 \\
h & Cross-section height (in) & 10 \\
b & Cross-section height (in) & 10 \\
A & Cross-section area (in^2) & 100 \\
E & Young’s Modulus (psi) & $30 \times 10^{6}$ \\
v & Poisson's ratio & 0.3 \\
G & Shear modulus (psi) & $11.54 \times 10^{6}$
\end{tabular}

The MOOSE displacement results were compared with a few different solution methods:

1) Closed form equation based on Bernoulli beam theory (with addition of shear deformation)

2) SAP2000, which is a beam/frame finite element software, and

3) Ansys, which is a high-fidelity finite element simulation software. 
SAP2000 is a software developed by Computers \& Structures, Inc. primarily for the analysis and design of frame structures. SAP2000 uses a 3D frame element formulation for performing FEA analysis of beams and frames, with considerations for bi-axial bending, torsion, axial, and shear deformations. Comparison to SAP2000 will give us the ability to compare a simpler FEA solution with the analytical equation. Ansys is a software developed by Ansys Inc. and is a high fidelity, multiphysics simulation environment which can model elements as full 3D solid elements. Comparison between MOOSE and Ansys should yield the closest results, after matching the mesh and element types, since both model the full 3D solid elements.

\subsection{Example 1 - Concentrated Load on Square Beam}

The first example focused on the bending analysis of a simply supported beam with a concentrated load at the center, shown in Figure 2.1. This example is a fundamental structural mechanics problem that has a simple closed-form solution to calculate the deformation response for comparison. The problem was performed with both a solid beam section (Example 1A), and a hollow section (Example 1B). The primary physics assessed with this example is the forcedeflection response of a beam which mimics the same type of response due to load pad contact.

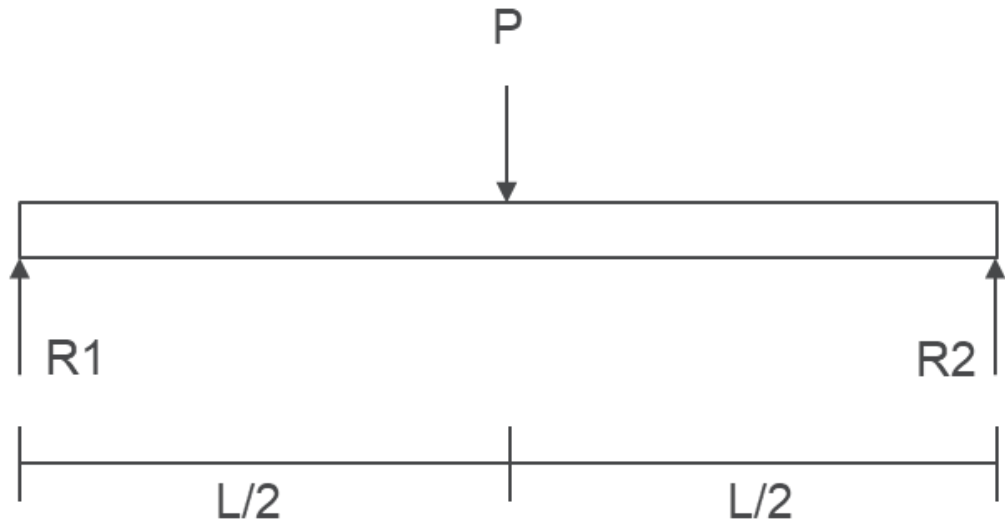

Figure 2.1. Simply supported beam with a concentrated force, $\mathrm{P}$, at the midspan, L/2.

The maximum deflection (with shear deformation considerations) occurs at the midspan and is given as the closed form equation:

$$
\delta_{\max }=\frac{P L^{3}}{48 E I}+\frac{P(L / 2)}{2 k A G}
$$

where $k$ is a parameter that is defined as the ratio of the shear area, Av, to the total cross-sectional area, A [3]. This equation is for the beam element formulation to calculate the deflection for any prismatic cross-section and is applicable to solid and hollow sections. 


\subsubsection{Example 1A - Solid Section}

The solid section mesh was created with the MOOSE Mesh Generator system and has an element size of $1 \mathrm{in}^{3}$. The mesh is shown in Figure 2.2. The value of the force, $\mathrm{P}$, was $3200 \mathrm{lb}$ applied at the midspan at the top of the 3D cross-section. The displacement from MOOSE is shown in Figure 2.3, correctly showing the displacement is 0 at the support edges and maximum at the center.

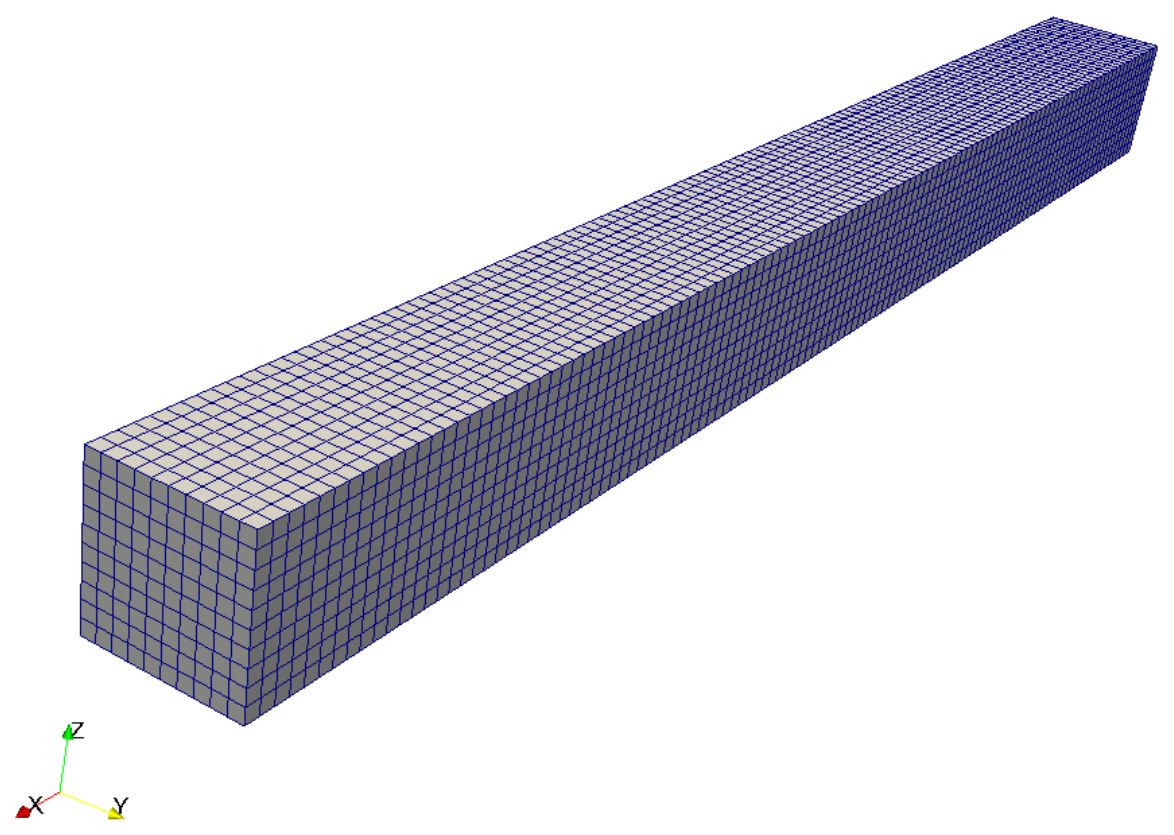

Figure 2.2. Solid beam mesh for Example 1A 


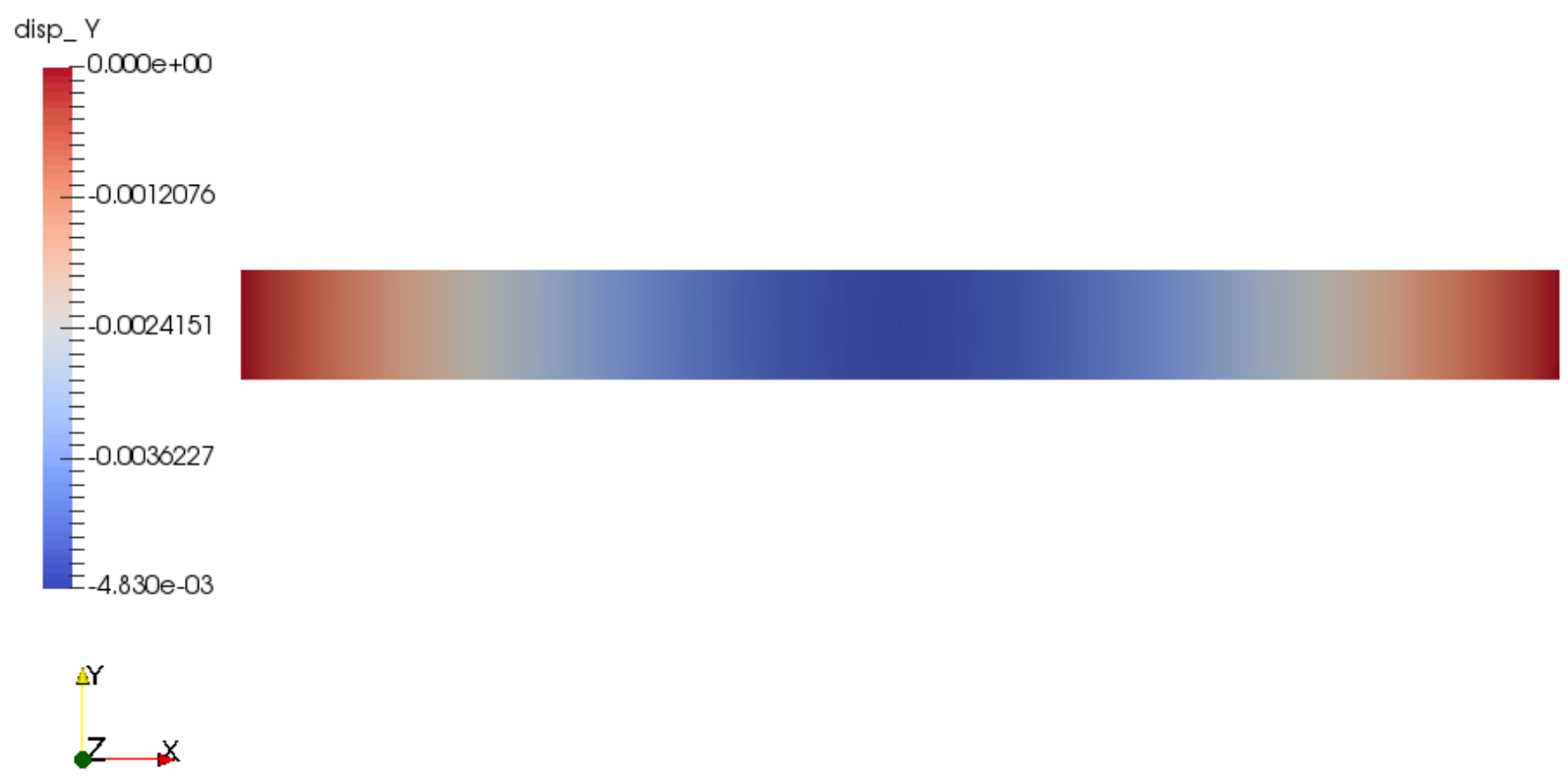

Figure 2.3. Deformation (in.) from MOOSE calculation for Example 1A for the displacement in the $\mathrm{Y}$ axis

The comparison between MOOSE, the closed form equation, the SAP2000 results, and the Ansys results are shown in Figure 2.4, with comparison of the max deflection results shown in Table 2.2 and the relative error shown in Table 2.3. The relative error at max deflection, compared to the equation for this case is $0.08 \%$, compared with SAP2000 is $0.43 \%$, and compared with Ansys is $0.84 \%$. The displacement results match very well between MOOSE and SAP2000 as well as compared to the closed form equation. 


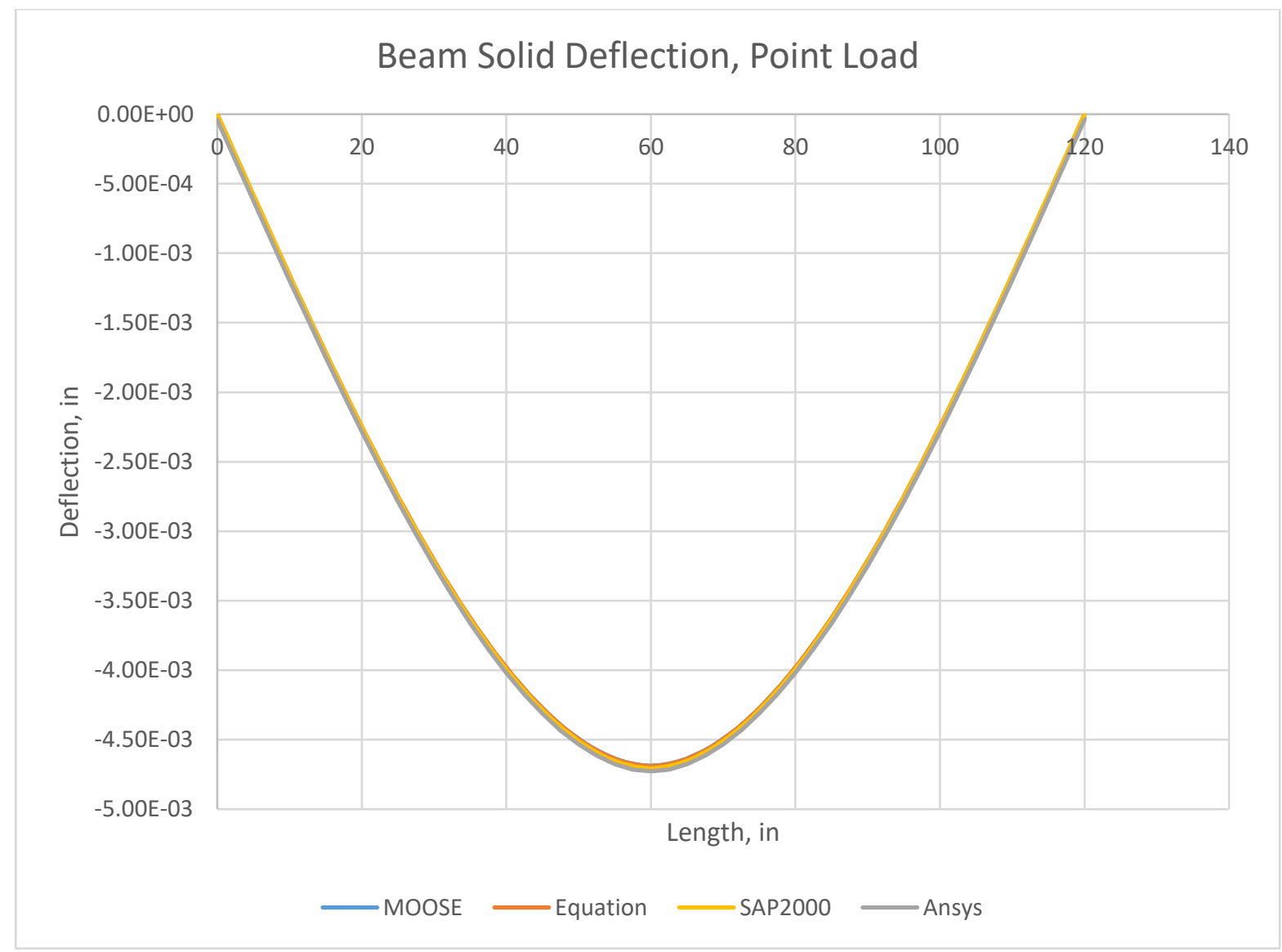

Figure 2.4. Displacement versus length from MOOSE deflection calculations with the closed form solution, SAP2000 results, and Ansys results

\subsubsection{Example 1B - Hollow Section}

The hollow section mesh was created with the MOOSE Mesh Generator system by removing the center portion of the solid section. The element size is $1 \mathrm{in}^{3}$. The mesh is shown in Figure 2.5. The value of the force, P, was $3200 \mathrm{lb}$ applied at the midspan at the top of the 3D cross-section. The displacement from the MOOSE calculations is shown in Figure 2.6, correctly showing the displacement is 0 at the support edges and maximum at the center. 


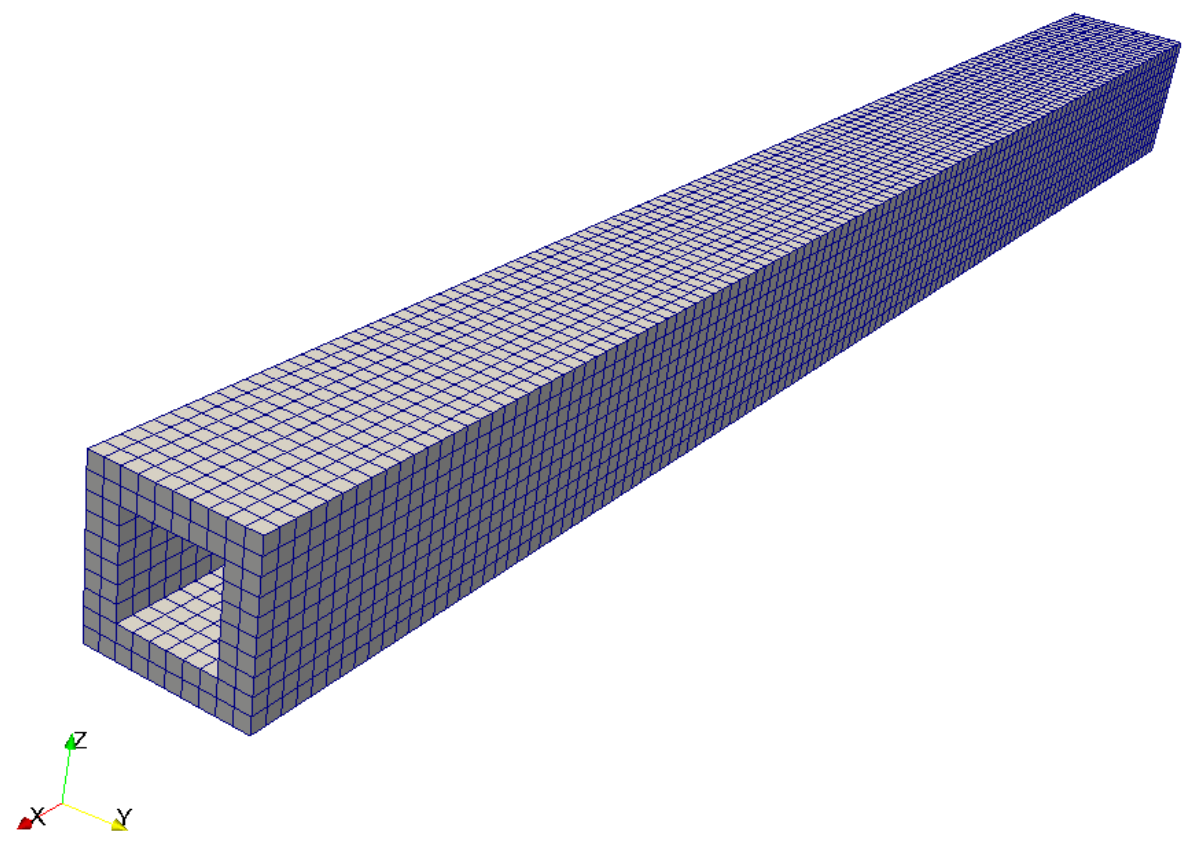

Figure 2.5. Hollow beam mesh for Example 1B

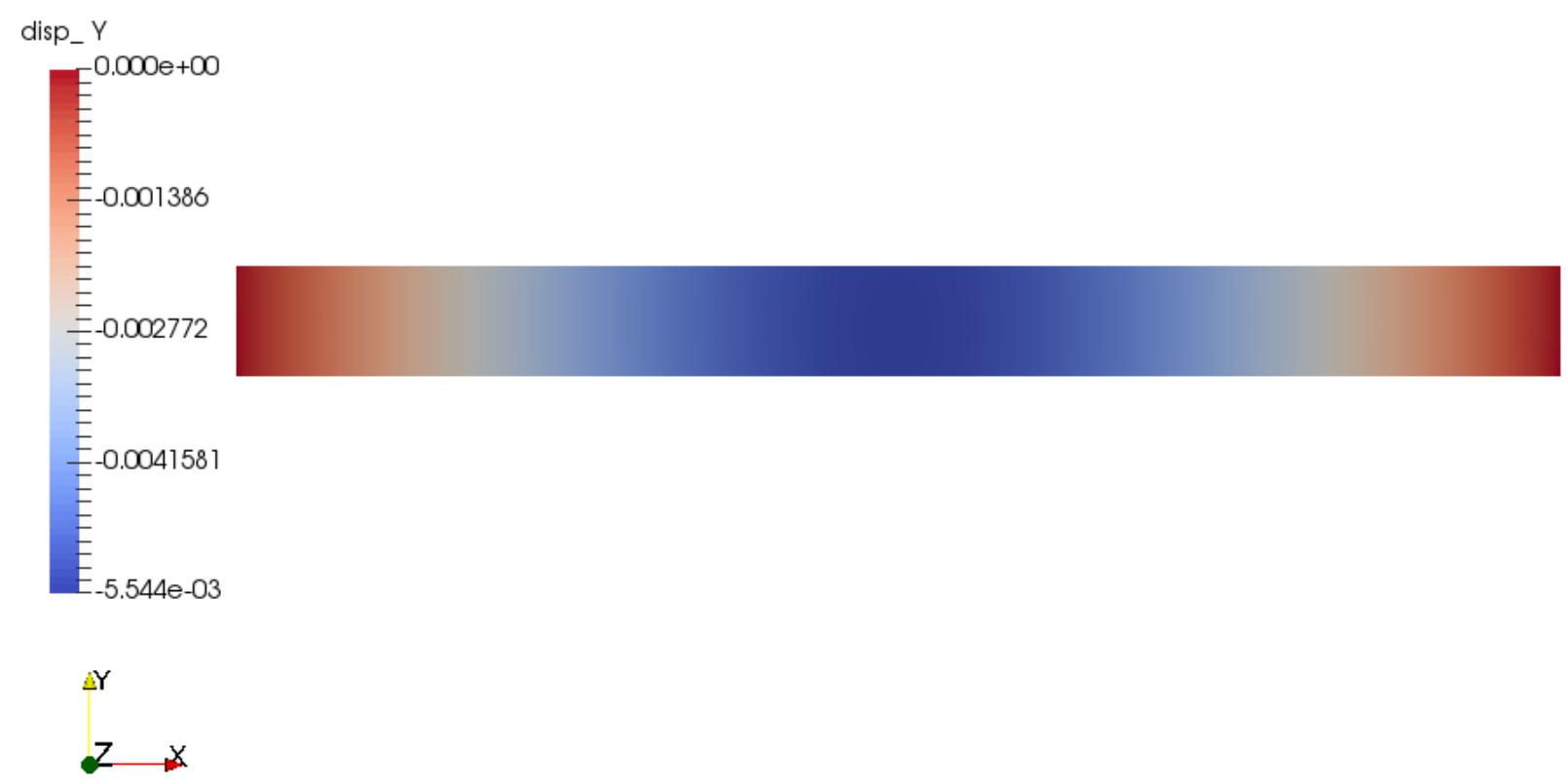

Figure 2.6. Deformation (in.) from MOOSE calculation for Example 1B for the displacement in the $\mathrm{Y}$ axis

The comparison between MOOSE, the closed form equation, the SAP2000 results, and the Ansys results are shown in Figure 2.7, with comparison of the max deflection results shown in 
Table 2.2 and the relative error shown in Table 2.3. The relative error at max deflection, compared to the equation for this case is $1.06 \%$, compared with SAP2000 is $0.12 \%$, and compared with Ansys is $0.44 \%$. The displacement results match very well across the different software calculations. The closed form equation slightly overestimates the deflection because of the difficulty in correctly estimating the shear area that is affected by the shear force along the beam length.

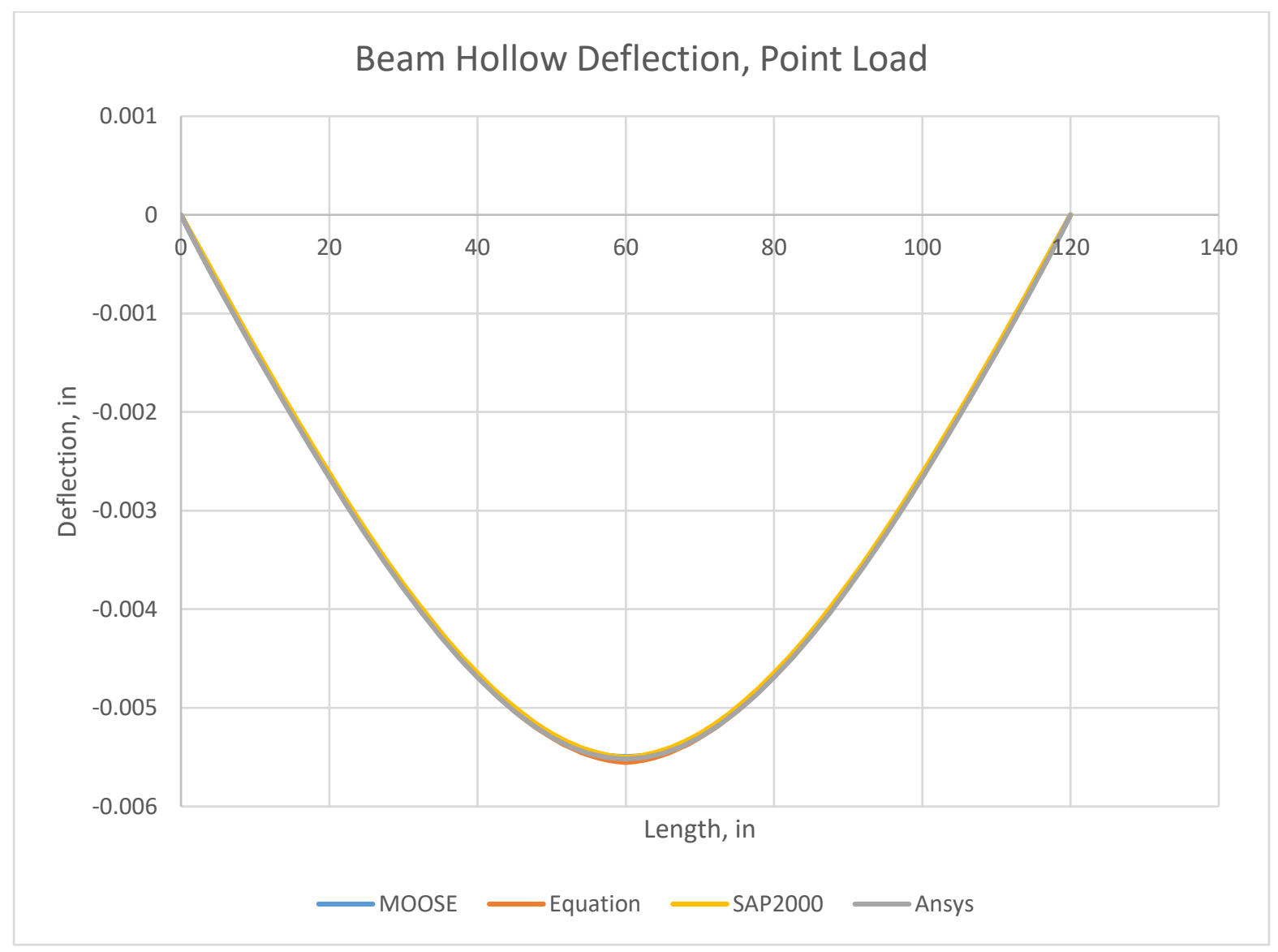

Figure 2.7. Displacement versus length from MOOSE deflection calculations with the closed form solution, SAP2000 results, and Ansys results

\subsection{Example 2 - Distributed Load on Square Beam}

The second example focused on the bending analysis of a simply supported beam with a uniformly distributed force along the span, shown in Figure 2.8. This is a fundamental structural mechanics problem with a simple closed-form solution to calculate the deformation response for comparison. This example was performed with both a solid beam section (Example 2A), and a hollow section (Example 2B). The primary physics assessed with this example is the forcedeflection response of a beam with a pressure distribution. Fuel assemblies under contact displace 
due to a contact pressure at the load pads in a restraint ring design for a ducted fuel assembly, so this example was selected to assess displacement under pressure loads.

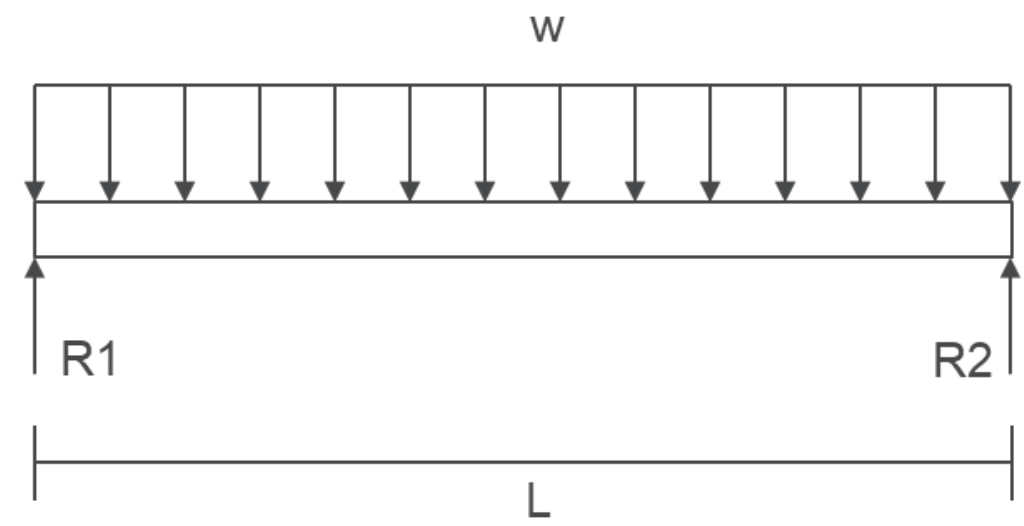

Figure 2.8. Simply supported beam with a uniformly distributed load, w, along the span, L.

The maximum deflection (with shear deformation considerations) occurs at the midspan and is given as:

$$
\delta_{\max }=\frac{5 w L^{4}}{384 E I}+\frac{w L^{2}}{2 k A G}
$$

where $k$ is a parameter that is defined as the ratio of the shear area, Av to the total cross-sectional area, A [3].

\subsubsection{Example $2 \mathrm{~A}$ - Solid Section}

Example 2A uses the same mesh as in Example 1A, shown in Figure 2.2. The force was applied as a uniform distributed pressure of 5 psi. The equivalent beam uniform loading is $500 \mathrm{lb} / \mathrm{in}$ since the beam is 10 in wide. The displacement from the MOOSE calculations is shown in Figure 2.9, correctly showing the displacement is 0 at the support edges and maximum at the center. 


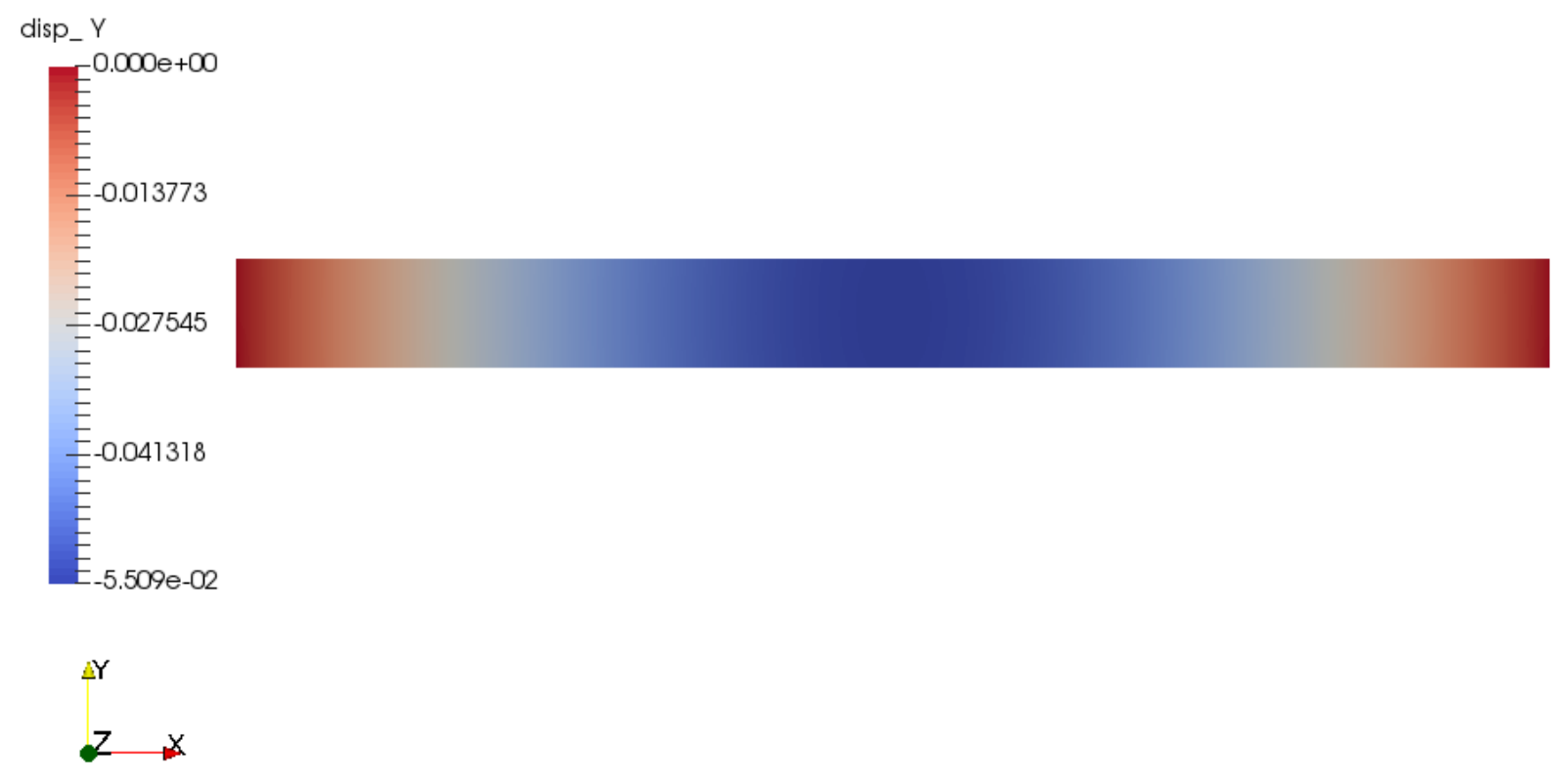

Figure 2.9. Deformation (in.) from MOOSE calculation for Example 2A for the displacement in the $\mathrm{Y}$ axis

The comparison between MOOSE, the closed form equation, the SAP2000 results, and the Ansys results are shown in Figure 2.10, with comparison of the max deflection results shown in Table 2.2 and the relative error shown in Table 2.3. The relative error at max deflection, compared to the equation for this case is $0.32 \%$, compared with SAP2000 is $0.04 \%$, and compared with Ansys is $0.30 \%$. The displacement results match very well across the different software calculations and compared to the closed form equation. 


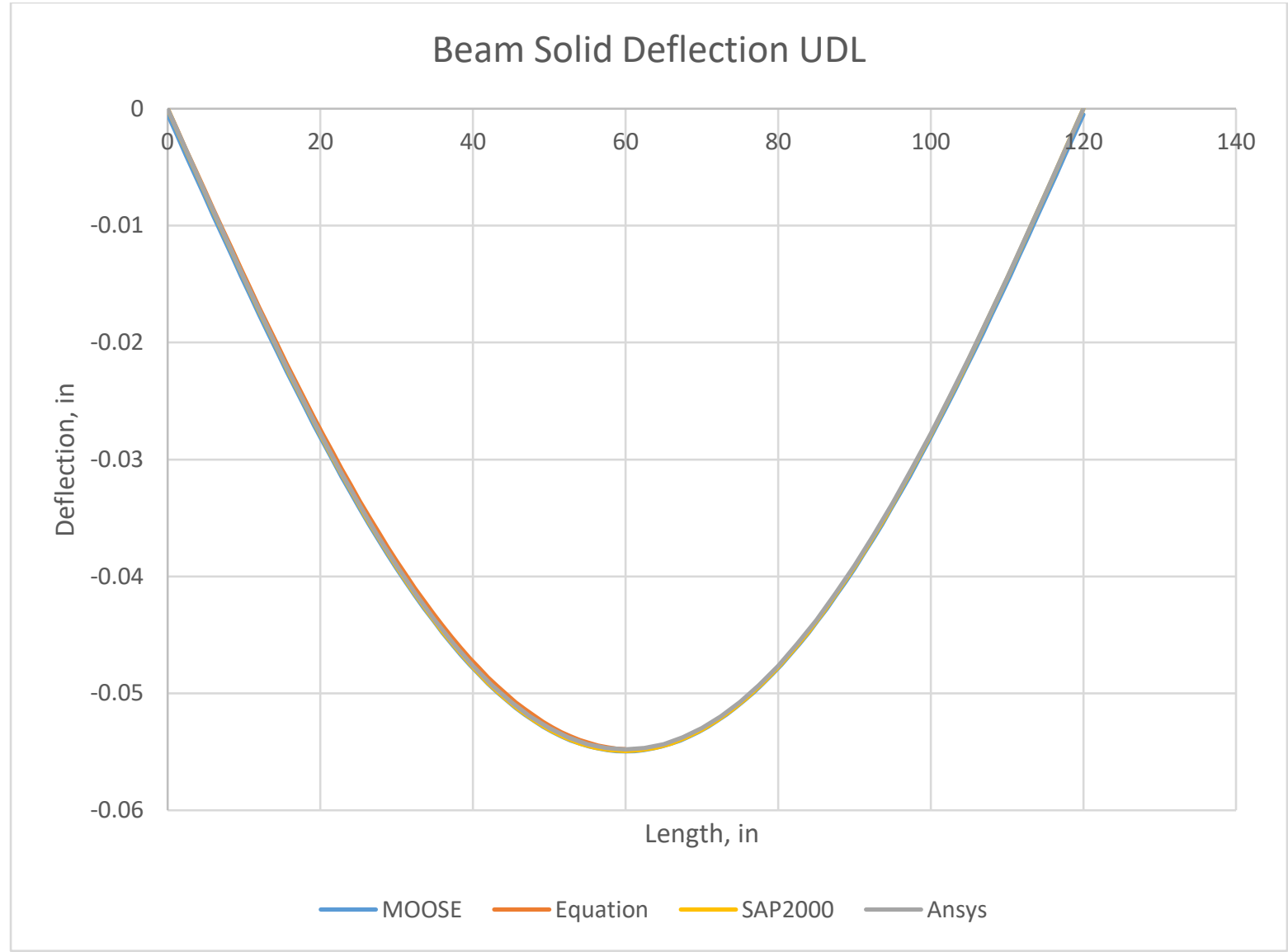

Figure 2.10. Displacement versus length from MOOSE deflection calculations with the closed form solution, SAP2000 results, and Ansys results

\subsubsection{Example 2B - Hollow Section}

Example 2B uses the same mesh as in Example 1B, shown in Figure 2.5. The force was applied as a uniform distributed pressure of 5 psi. The equivalent beam uniform loading is $500 \mathrm{lb} / \mathrm{in}$ since the beam is 10 in wide. The displacement from the MOOSE calculations is shown in Figure 2.11, correctly showing the displacement is 0 at the support edges and maximum at the center. 


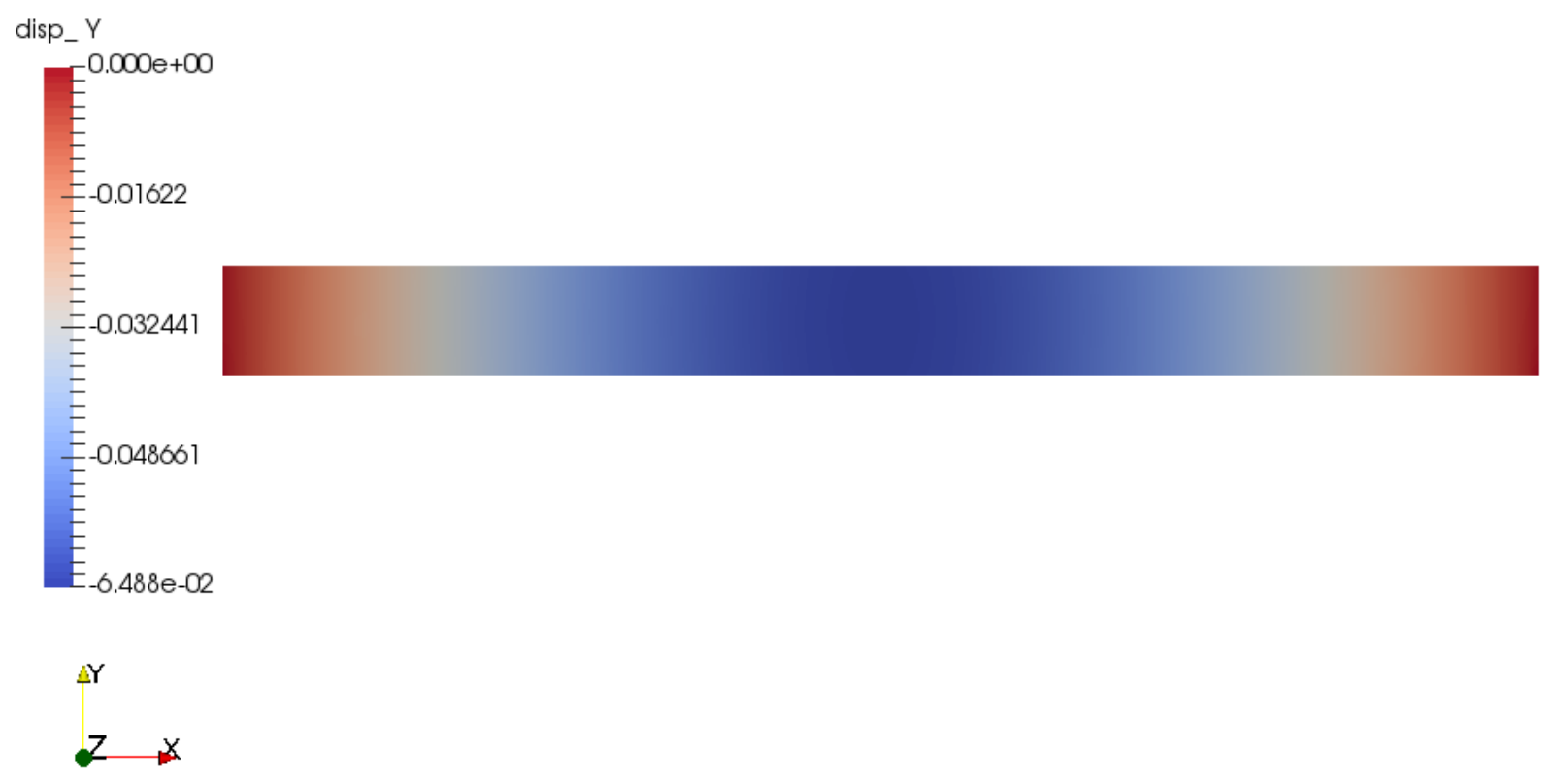

Figure 2.11. Deformation (in.) from MOOSE calculation for Example 2B for the displacement in the $\mathrm{Y}$ axis

The comparison between MOOSE, the closed form equation, the SAP2000 results, and the Ansys results are shown in Figure 2.12, with comparison of the max deflection results shown in Table 2.2 and the relative error shown in Table 2.3. The relative error at max deflection, compared to the equation for this case is $0.12 \%$, compared with SAP2000 is $0.12 \%$, and compared with Ansys is $0.51 \%$. The displacement results match very well across the different software calculations. The closed form equation slightly underestimates the displacement because of the difficulty in correctly estimating the shear area that is affected by the shear force along the beam length. 


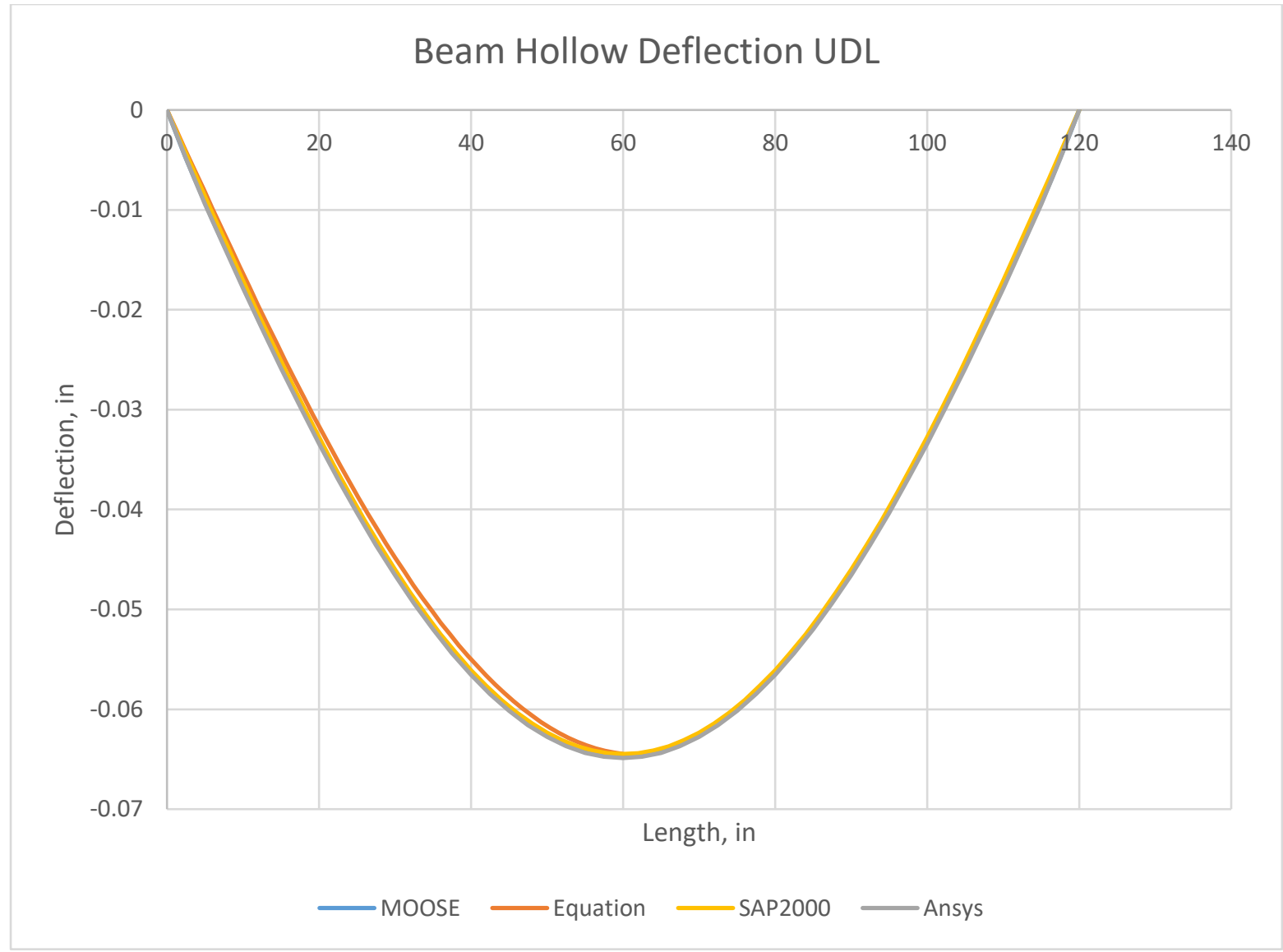

Figure 2.12. Displacement versus length from MOOSE deflection calculations with the closed form solution, SAP2000 results, and Ansys results

\subsection{Example 3 - Distributed Load on Hexagonal Duct}

The third example assesses the capability of MOOSE to calculate the deformation response with a hexagonal, thin-walled duct cross-section. This cross-section matches the cross-section used in liquid cooled fast reactor core designs, so the ability for MOOSE to accurately calculate the deformation is critical to reactor analysis. The loading is identical to Example 2, with a 5 psi pressure applied to the top face of the duct, with an equivalent beam load of $15.1 \mathrm{lb} / \mathrm{in}$ along the length of the beam. The hex duct cross section is shown in Figure 2.13, with the across-flats dimension, D, equal to 5.232 in, the side face width, s, equal to $3.02 \mathrm{in}$, and the wall thickness, $\mathrm{t}$, equal to $0.1181 \mathrm{in}$. The meshed model is shown in Figure 2.14. 


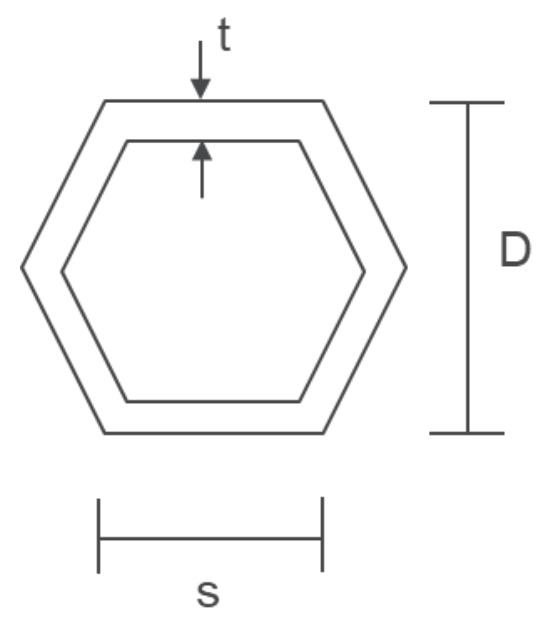

Figure 2.13. Cross section for hex duct model

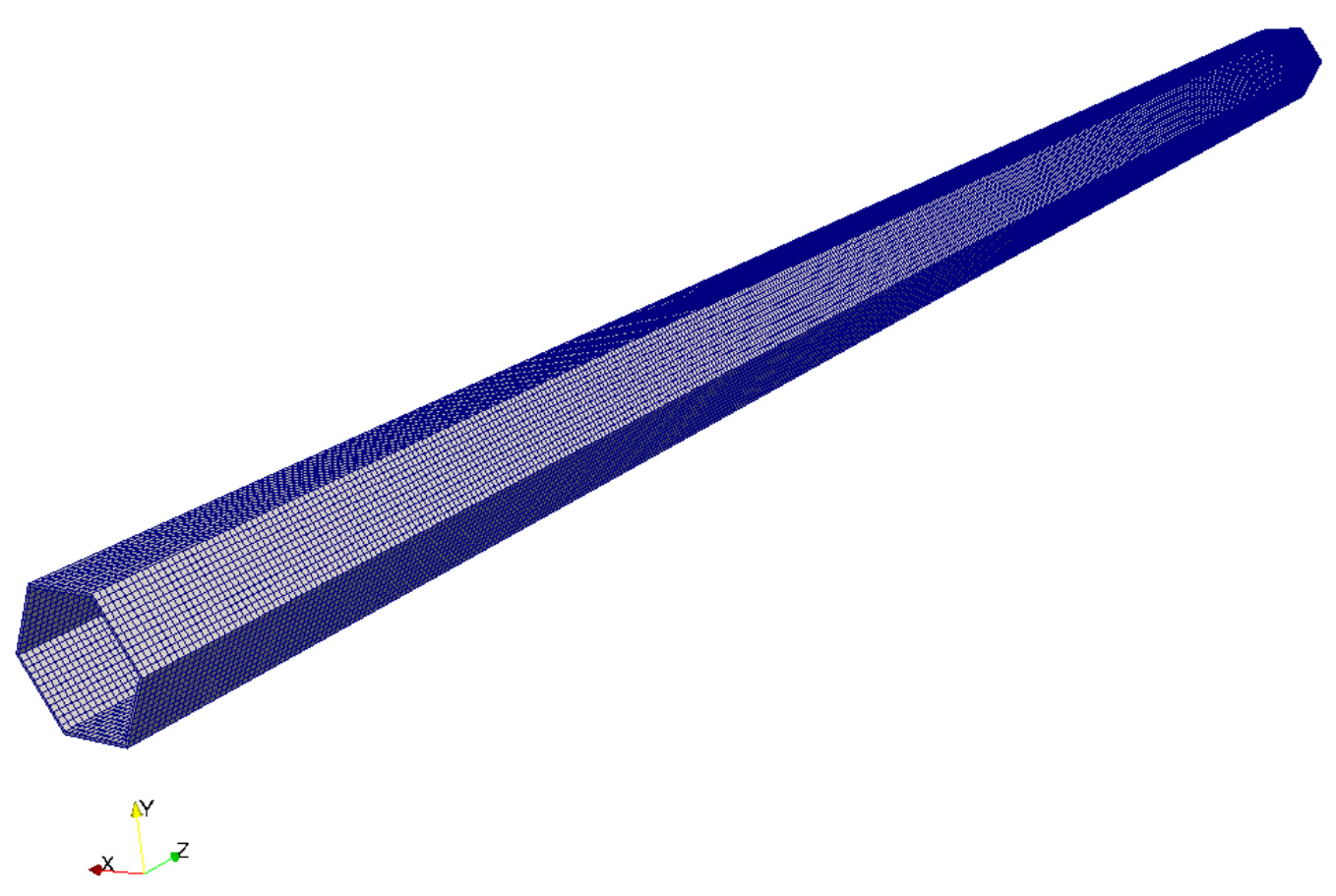

Figure 2.14. Hex duct mesh for Example 3

The displacement from the MOOSE calculations is shown in Figure 2.15, correctly showing the displacement is 0 at the support edges and maximum at the center. The maximum deformation shown in the figure is slightly overestimated compared to the centerline deformation, due to the thin-walled face supporting the bearing pressure. 


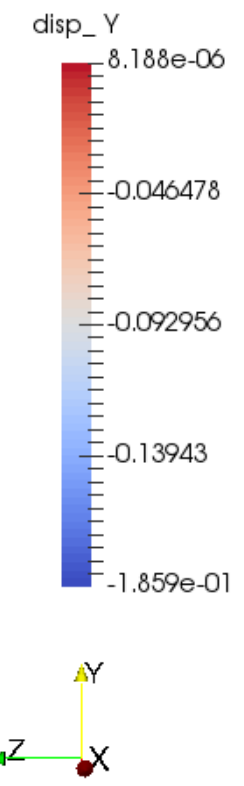

Figure 2.15. Deformation (in.) from MOOSE calculation for Example 3 for the displacement in the $\mathrm{Y}$ axis

The comparison between MOOSE, the closed form equation, the SAP2000 results, and the Ansys results are shown in Figure 2.16, with comparison of the max deflection results shown in Table 2.2 and the relative error shown in Table 2.3. The relative error at max deflection, compared to the equation for this case is $0.90 \%$, compared with SAP2000 is $0.80 \%$, and compared with Ansys is $0.09 \%$. The displacement results match very well across the different software calculations. The closed form equation underestimates the deflection because of the difficulty in correctly estimating the shear area that is affected by the shear force along the beam length especially due to hexagonal and thin-walled cross section. The MOOSE results agree much better with the Ansys results since both simulations were performed with a full 3D cross-section with the same size mesh. 


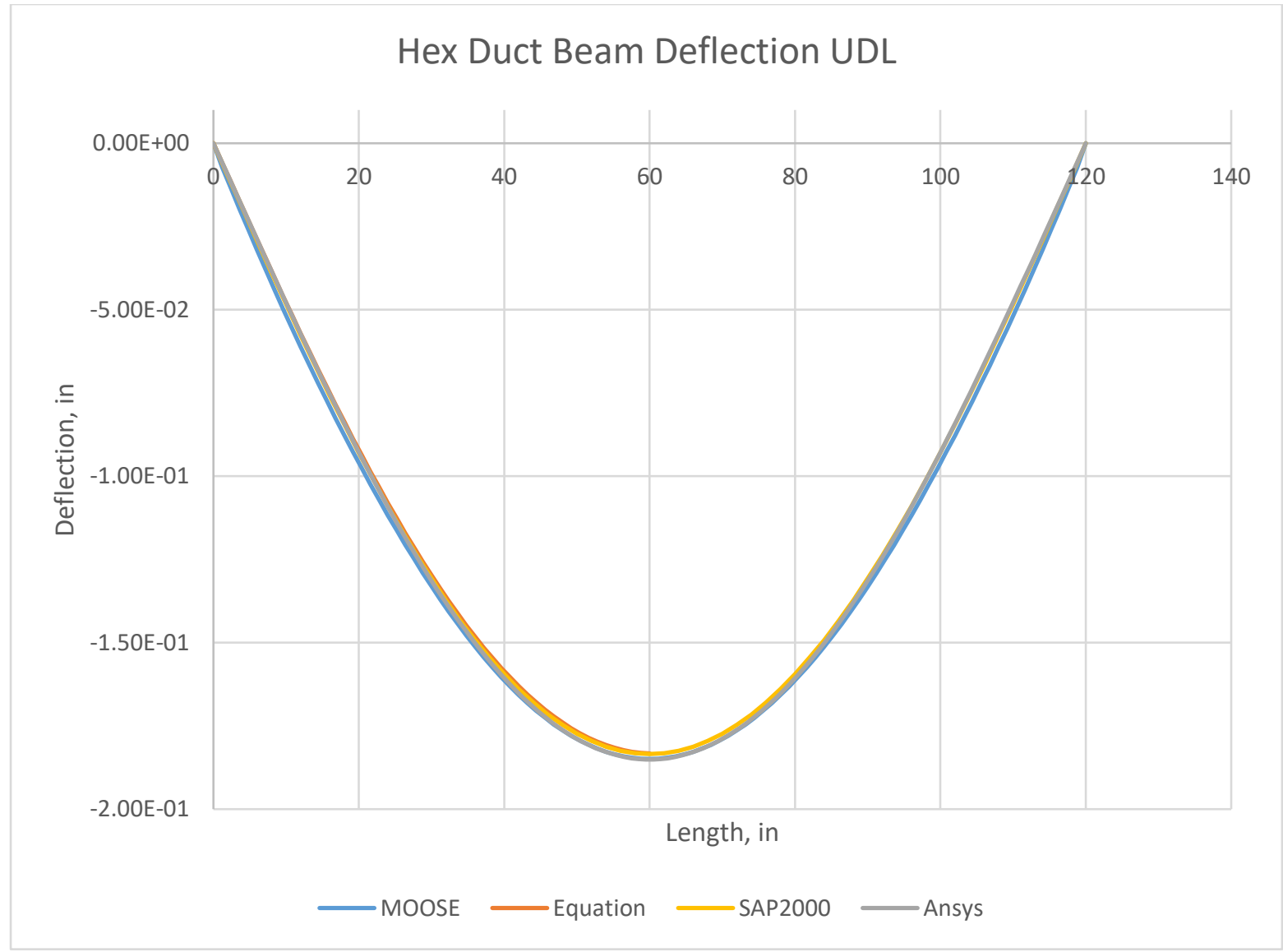

Figure 2.16. Displacement versus length from MOOSE deflection calculations with the closed form solution, SAP2000 results, and Ansys results

\subsection{Example 4 - Concentrated Load on Cantilever Square Beam}

This example focused on the bending analysis of a fixed-end, cantilever beam with a concentrated load at the free end, shown in Figure 2.17. This example has a simple closed-form solution to calculate the deformation response for comparison. The primary physics assessed with this example is the force-deflection response of a beam which mimics the same type of response due to load pad contact and more closely resembles a duct deformation problem, since the fuel ducts are similar to cantilever beams depending on the nozzle boundaries. 


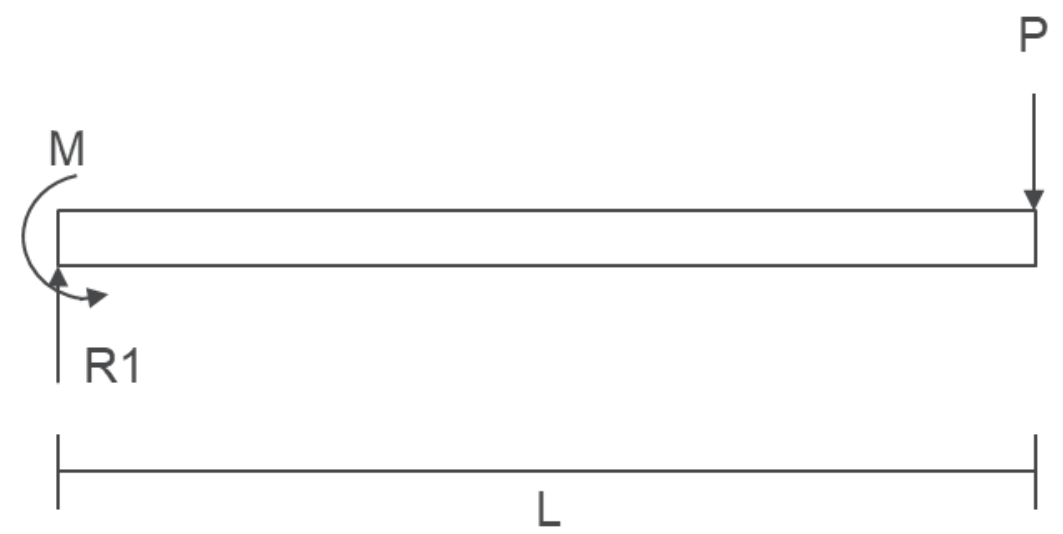

Figure 2.17. Cantilever beam with a concentrated force, $\mathrm{P}$, at the free end

Example 4 used the same mesh as in Example 1A, shown in Figure 2.2. The value of the force, $\mathrm{P}$, was $500 \mathrm{lb}$ applied at the centerline of the cross-section at the free end. The displacement from the MOOSE calculations is shown in Figure 2.18, correctly showing the displacement is 0 at the supported end and maximum at the free end.

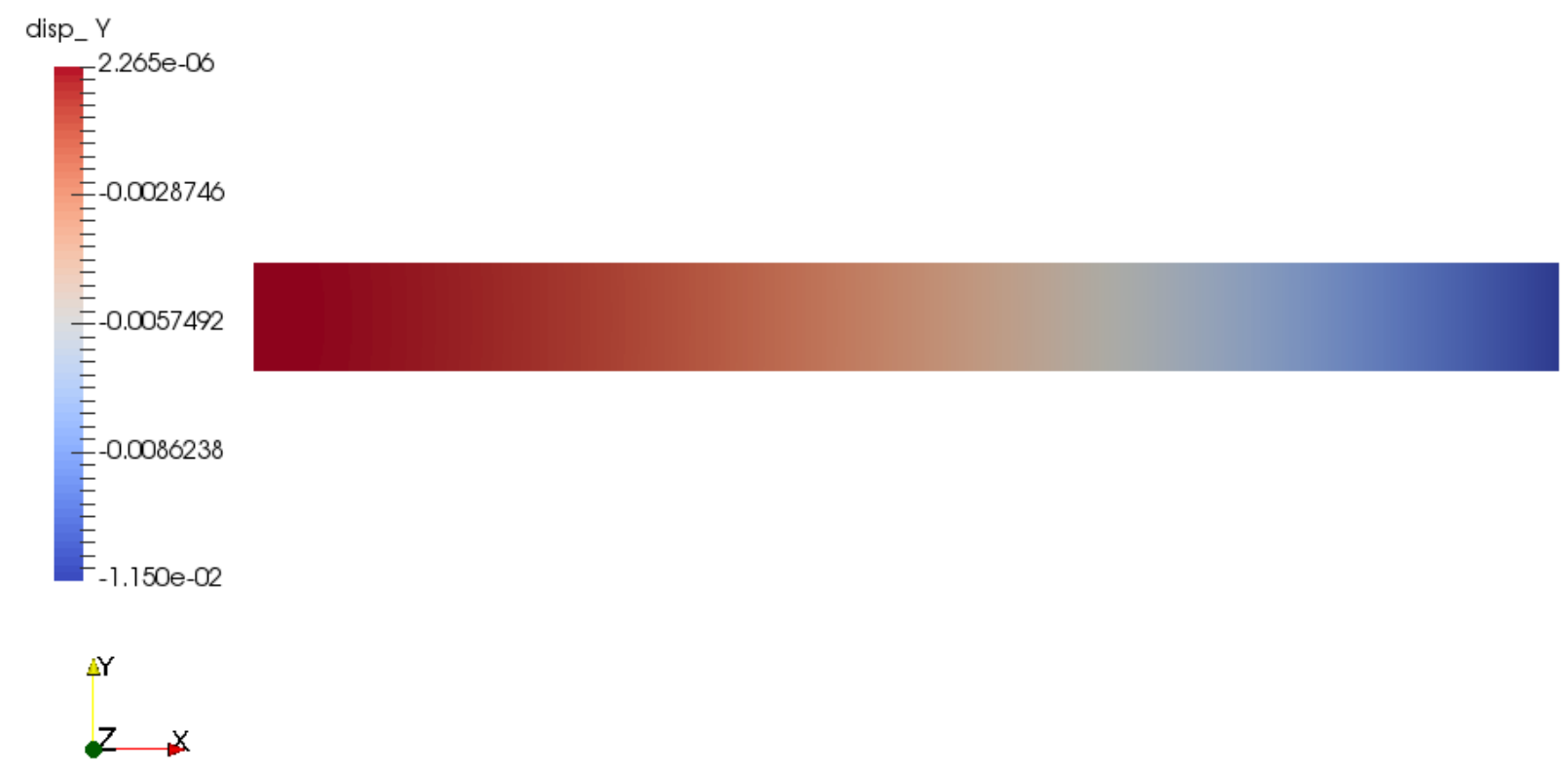

Figure 2.18. Deformation (in.) from MOOSE calculation for Example 4 for the displacement in the $\mathrm{Y}$ axis

The comparison between MOOSE, the closed form equation, the SAP2000 results, and the Ansys results are shown in Figure 2.19, with comparison of the max deflection results shown in Table 2.2 and the relative error shown in Table 2.3. The relative error at max deflection, compared to the equation for this case is $0.23 \%$, compared with SAP2000 is $0.31 \%$, and compared with 
Ansys is $0.18 \%$. The displacement results match very well across the different software calculations.

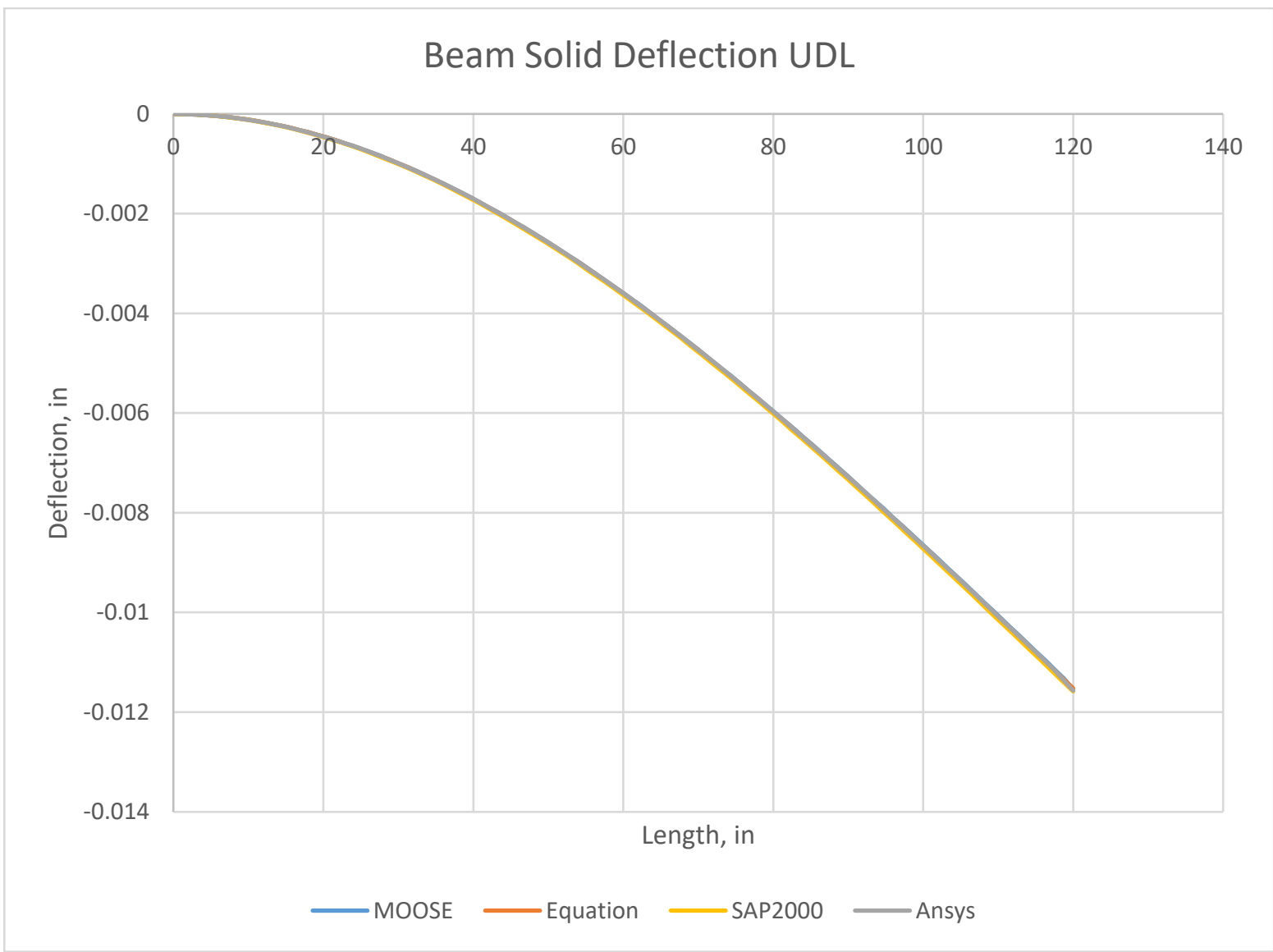

Figure 2.19. Displacement versus length from MOOSE deflection calculations with the closed form solution, SAP2000 results, and Ansys results

\subsection{Example 5 (IAEA Verification Problem 1)}

This example examines the free (unrestrained) thermal bowed deformation of a single, hexagonal assembly $4000 \mathrm{~mm}$ in height, fixed at the bottom. The problem specifications come from a working group for the verification and validation of Liquid Metal Fast Breeder Reactor (LMFBR) analysis codes organized by The International Atomic Energy Agency (IAEA) called the International Working Group on Fast Reactors (IWGFR). The coordinated work was performed by eleven participating agencies in nine different countries referenced in [4].

The IAEA verification problem 1 assembly has a linearly varying thermal gradient along the axial height in the active core region, shown in Figure 2.20. Below the core, all the corners have the same temperature of $400^{\circ} \mathrm{C}\left(752^{\circ} \mathrm{F}\right)$. The duct temperature from core inlet to core outlet varies linearly to $550^{\circ} \mathrm{C}\left(1022^{\circ} \mathrm{F}\right)$ at Corner $4,537.5^{\circ} \mathrm{C}\left(999.5^{\circ} \mathrm{F}\right)$ at Corners 3 and $5,512.5^{\circ} \mathrm{C}\left(954^{\circ} \mathrm{F}\right)$ at 
Corners 2 and 6 , and $500^{\circ} \mathrm{C}\left(932^{\circ} \mathrm{F}\right)$ at Corner 1 ; the temperature remains at these constant temperatures from the core outlet to the top of the duct, shown in Figure 2.21.

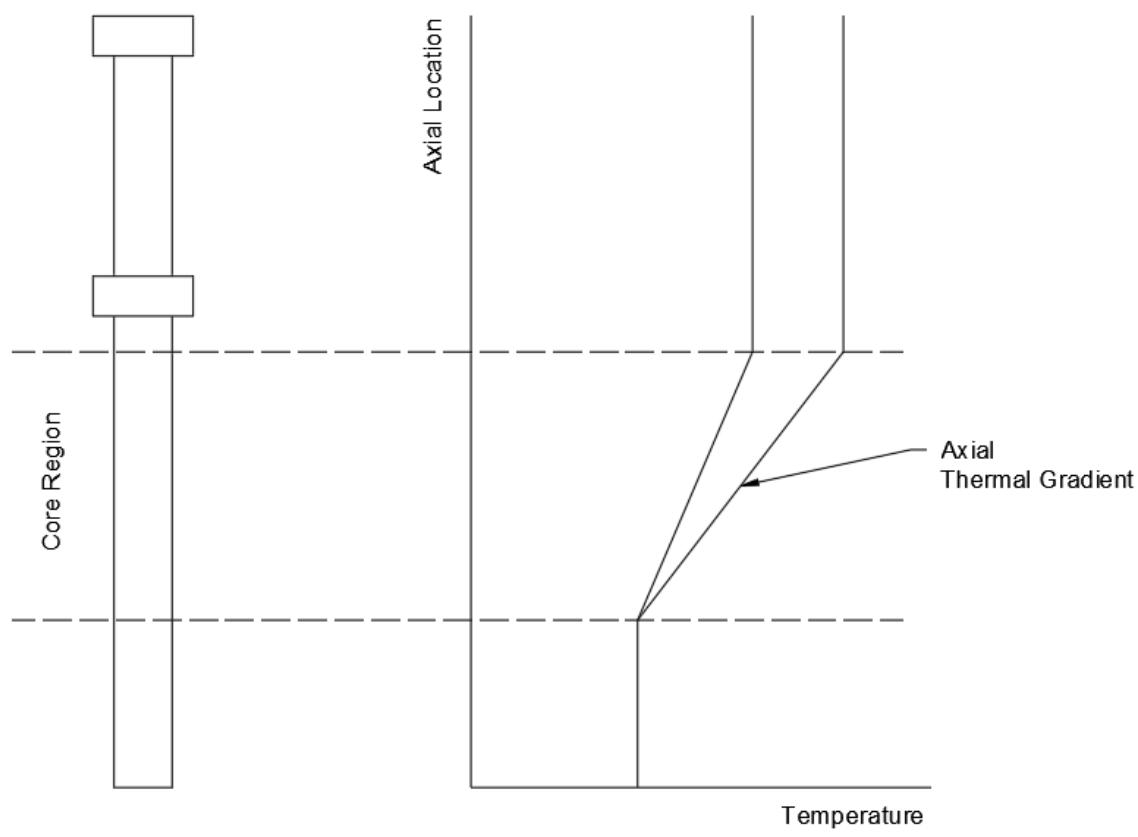

Figure 2.20. Schematic showing the thermal gradient developed axially along the core region of the duct, showing the temperature difference achieved along the corners directions

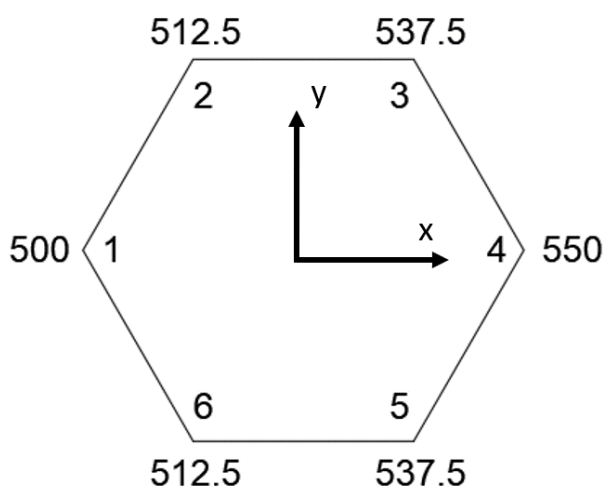

Figure 2.21. Maximum corner temperatures at the top of the core region

Example 5 used the same geometric parameters as Example 3. The temperature distribution was prescribed on each outside face of the hexagonal cross-section along the height and is shown in Figure 2.22 along with the displacement from the MOOSE calculations. The view presented in the figure is along the (6-5) face view from Figure 2.21, which has a maximum temperature on the right side (positive $\mathrm{x}$ axis) of $550^{\circ} \mathrm{C}$ and a minimum temperature on the left side (negative $\mathrm{x}$ axis). 
This tends to bow the duct from right to left in the negative $\mathrm{x}$ direction. The analytical solution provided in [4] is 0.4823 in for the tip deflection, while MOOSE calculates a value of $0.4807 \mathrm{in}$, a difference of only $0.34 \%$.
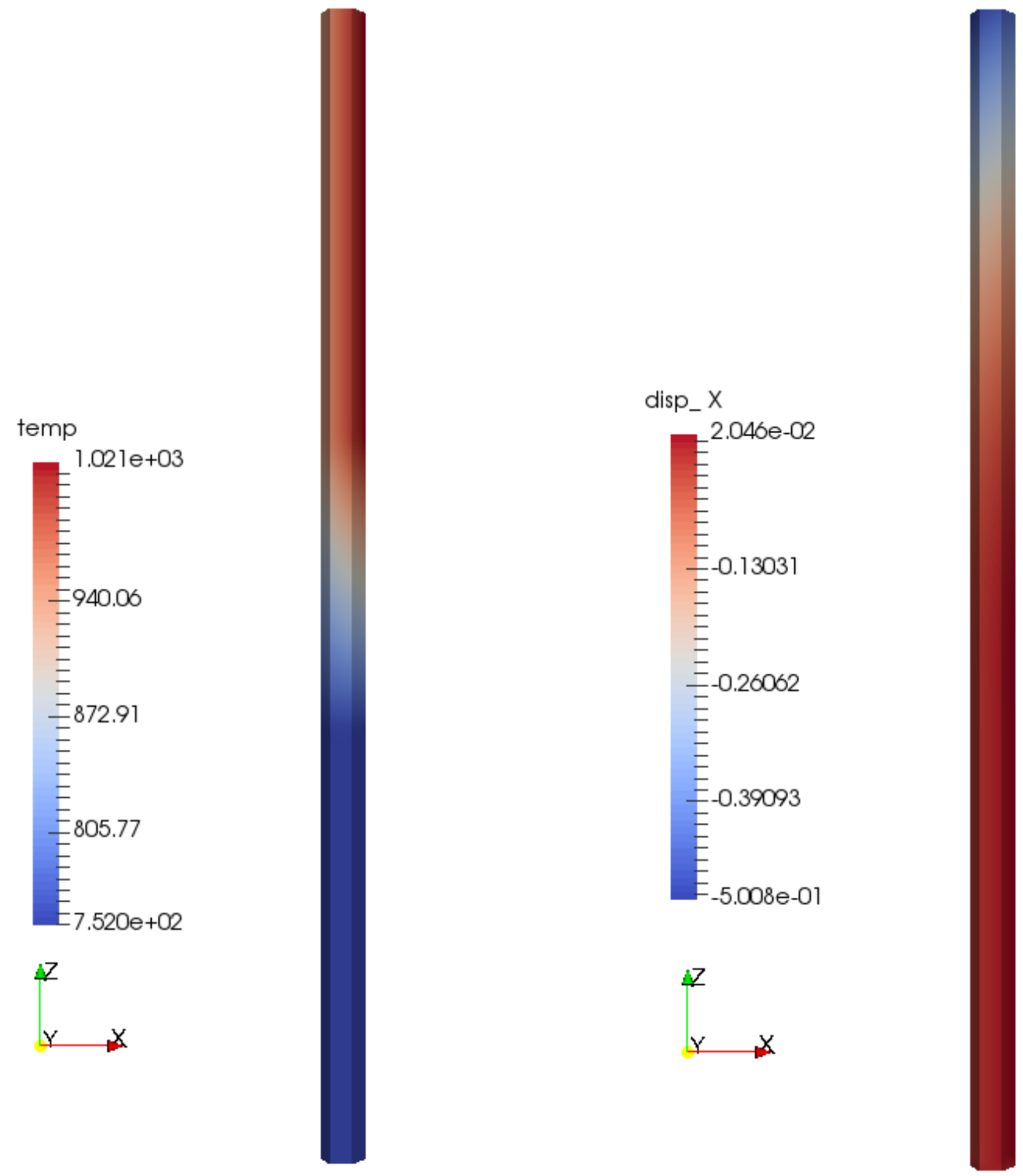

Figure 2.22. Temperature gradient (left) in ${ }^{\circ} \mathrm{F}$, and the displacement (right).

\subsection{Example 6 (IAEA Verification Problem 3A)}

This example examines the behavior of a single duct thermally bowing into a $60^{\circ}$ symmetric sector of a core with free boundaries around the symmetric lines (Figure 2.23). The dashed red lines indicate the location of the free boundary, and the blue arrow indicates the direction of the 
thermal bow, corner to corner along the duct cross section. The desired outputs are the interactions between ducts at the ACLP and TLP contact locations.

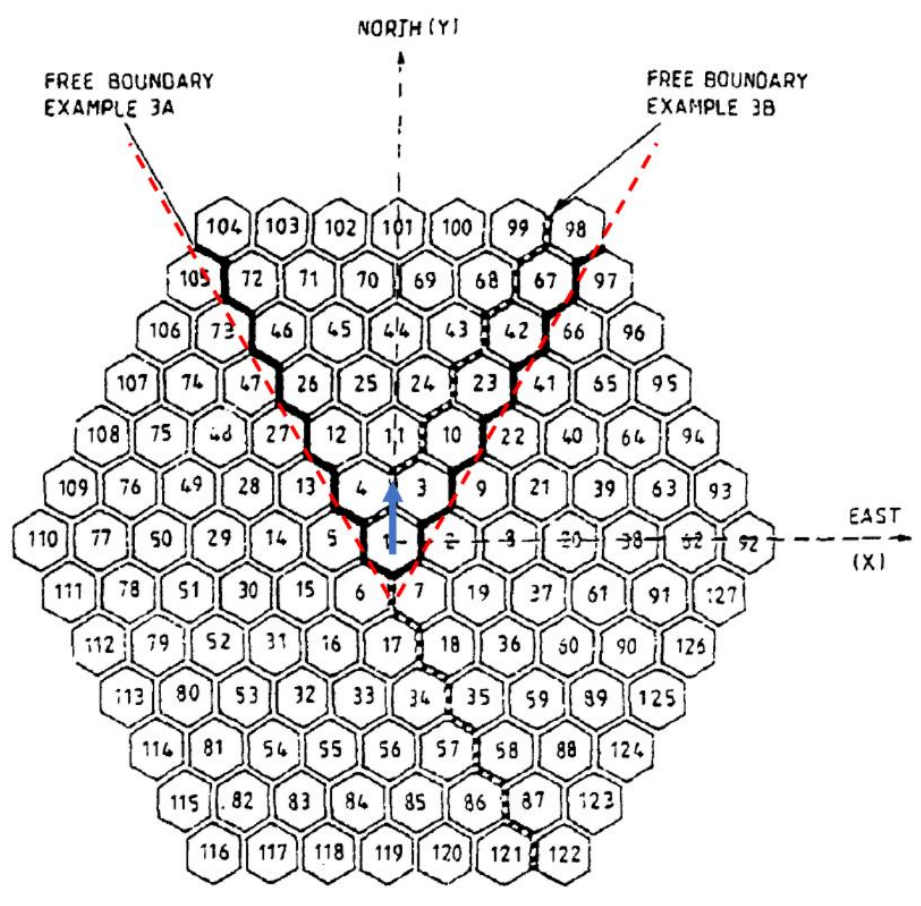

Figure 2.23. Model for IAEA VP3A of $60^{\circ}$ symmetric core region with a free boundary, represented by the red dashed line. The blue arrow indicates the direction of the thermal gradient induced bow for duct 1 (Adapted from [4] @ IAEA).

An initial version of this problem has been set up and run using the MOOSE Contact and Tensor Mechanics modules. This model, shown in Figure 2.24, simulates the response of Ducts 1, 3, 10, and 11, the locations of which are shown in Figure 2.23. It is expected that Ducts 1, 3, 4, 10, and 12 will deform under this loading. Because of the symmetric nature of the deformation, it is not necessary to model Ducts 4 and 12. Although it was not expected to deform, Duct 11 was included in the model to verify that assumption. 

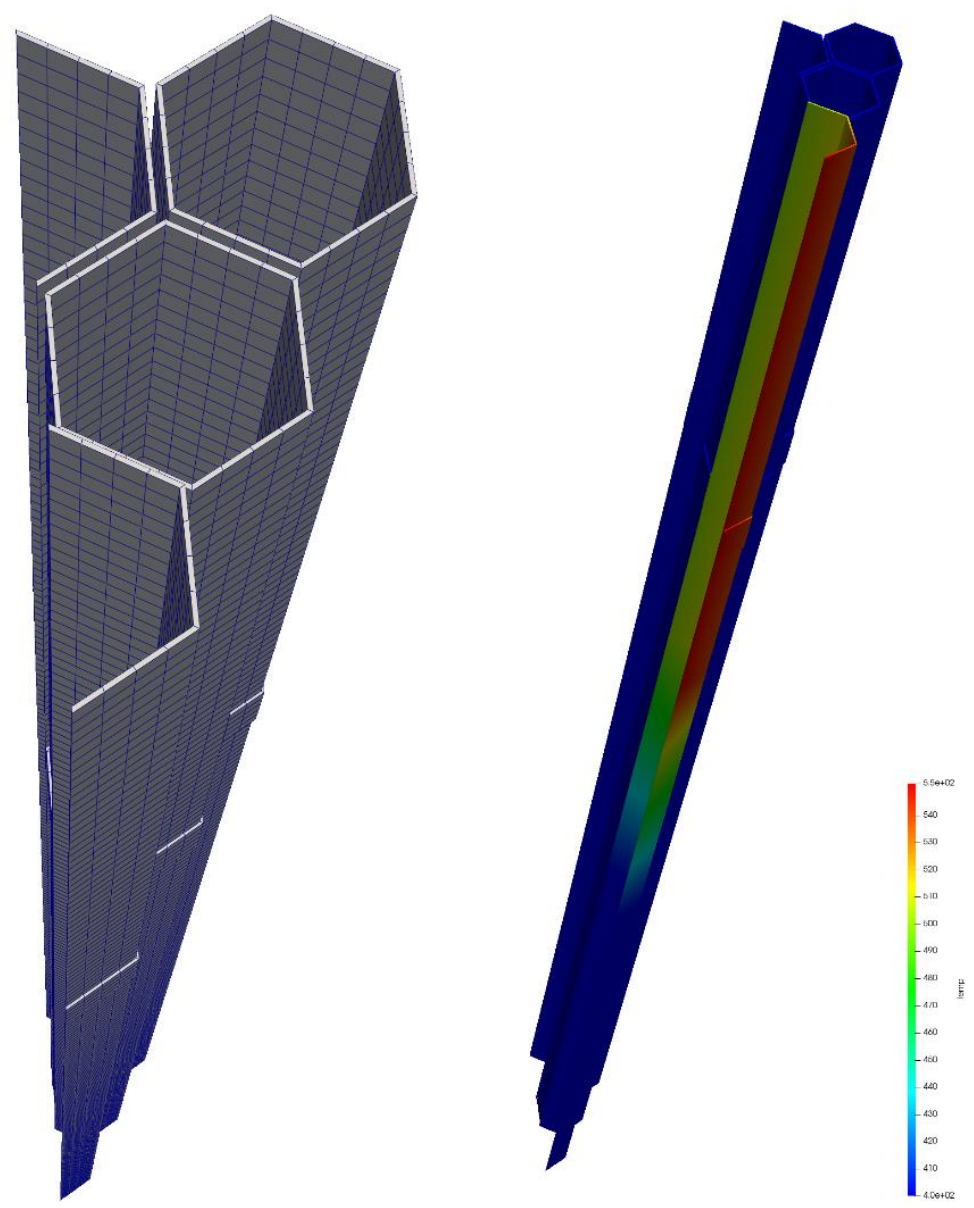

Figure 2.24. MOOSE model of ducts $1,3,10$, and 11 in IAEA VP3A. Shown are (left) the deformed mesh looking from the top of the ducts, and (right) the prescribed temperature field on duct 1 . The y-plane is used as a symmetry plane in this model.

For 3D problems, MOOSE currently only provides a node/face contact algorithm, in which primary and secondary surfaces must be defined for each contact interaction. It is somewhat challenging to use that algorithm for large-scale multi-body problems because the two interacting surfaces must be defined for every interaction. A mortar contact capability that permits self-contact or contact between faces belonging to the same identified surface, is in development, and currently only works in 2D. When this is fully developed, it will greatly simplify the setup and solution robustness of problems like this. This problem involves a small enough set of surfaces that defining the individual contact interactions is still feasible, however. Penalty contact with a frictionless model was used in this model.

To facilitate the solution of this nonlinear problem, the thermal gradient was gradually applied, so that the neighboring ducts would incrementally deform and come into contact with each other. In this quasistatic analysis, the full thermal gradient was applied at a pseudotime of 1.0. Figure 2.25 shows the time history of the average displacement at the top of each of the modeled ducts 
over the process of applying the thermal gradient. Duct 1 initially deforms, and comes into contact with Duct 3, which then comes in contact with Duct 10 late in the analysis. Duct 11 exhibits a very small amount of deformation because Duct 10 comes into contact with Duct 11 at the end of the loading process. The deformation of Duct 1 can be clearly seen in the image of the deformed mesh in Figure 2.24. The final displacements computed here are in reasonable agreement with those computed by participants in the IAEA benchmark, as reported in [4]. Further verification of the results from this model is still needed, but this simulation indicates that is feasible to solve this class of problem with MOOSE.

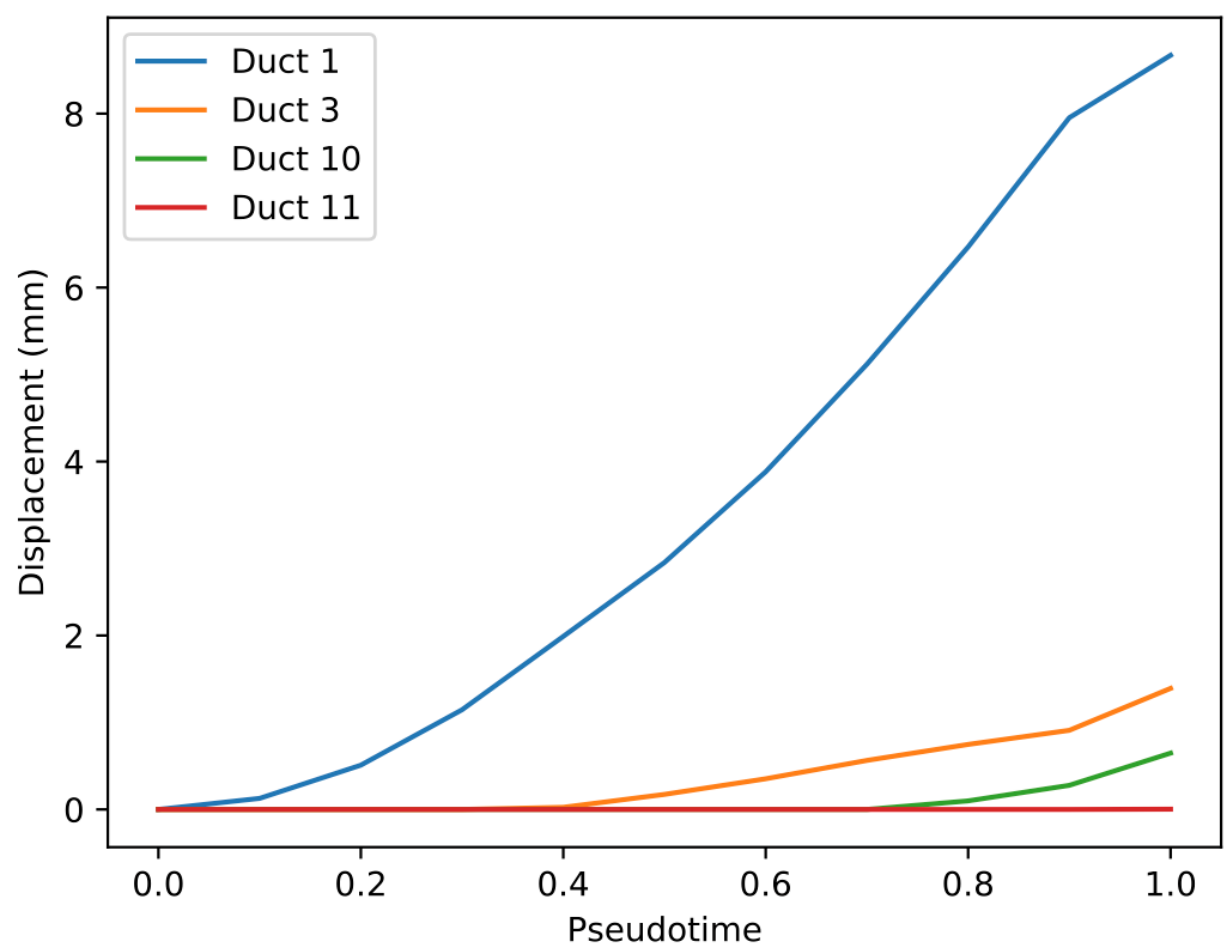

Figure 2.25. History of y-component of displacement at the top of the four ducts modeled in the process of incrementally applying the prescribed thermal gradient. The full thermal gradient is applied at time $=1.0$.

\subsection{Comparison of Example Results}

The table below summarizes all the MOOSE maximum deflection calculation results with those obtained from analytical solutions (closed form equations specified earlier in the report). The minimum percentage difference is only $0.34 \%$ while the maximum is $1.06 \%$ for the hollow section under concentrated force, which is well within any expected error due to the solid cross-section deformation and consideration of number of nodes along the length of the beams. Excellent agreement with analytical results is therefore observed for distributed and uniform loads on square beams (solid, hollow), distributed load on a hexagonal duct, concentrated load on a cantilever 
beam, and differential thermal gradient on a hexagonal duct. Collectively, these results indicate that the MOOSE Tensor Mechanics module will be able to accurately model deflections of single hexagonal ducts due to pressure loads or thermal gradients.

Table 2.2. Comparison of maximum centerline deflection results between MOOSE, the analytical equations, SAP200, and Ansys

\begin{tabular}{lcccc}
\hline \hline & Analytical (in) & MOOSE (in) & SAP2000 (in) & Ansys (in) \\
\hline Example 1A & 0.00469 & 0.00469 & 0.00471 & 0.00473 \\
Example 1B & 0.00555 & 0.00550 & 0.00550 & 0.00552 \\
Example 2A & 0.0549 & 0.0550 & 0.0549 & 0.0548 \\
Example 2B & 0.0645 & 0.0646 & 0.0645 & 0.0649 \\
Example 3 & 0.183 & 0.185 & 0.183 & 0.185 \\
Example 4 & 0.0115 & 0.0116 & 0.0116 & 0.0116 \\
Example 5 & 0.482 & 0.481 & - & -
\end{tabular}

Table 2.3. Error percentage of maximum centerline deflection results between MOOSE, the analytical equations, SAP200, and Ansys

\begin{tabular}{lccc}
\hline \hline & Analytical (\%) & SAP2000 $(\%)$ & Ansys $(\%)$ \\
\hline Example 1A & 0.08 & 0.43 & 0.84 \\
Example 1B & 1.06 & 0.12 & 0.44 \\
Example 2A & 0.32 & 0.04 & 0.30 \\
Example 2B & 0.12 & 0.12 & 0.51 \\
Example 3 & 0.90 & 0.80 & 0.09 \\
Example 4 & 0.23 & 0.31 & 0.18 \\
Example 5 & 0.34 & - & -
\end{tabular}


Table 2.4. Summary of the example problems for MOOSE assessment

\begin{tabular}{|c|c|c|c|c|c|}
\hline Problem & Description & Physics & $\begin{array}{l}\text { MOOSE Run } \\
\text { Completed? }\end{array}$ & $\begin{array}{l}\text { Code or Analytical } \\
\text { Comparison }\end{array}$ & Results \\
\hline $\begin{array}{l}\text { 1A. Concentrated } \\
\text { force beam bending }\end{array}$ & $\begin{array}{l}\text { Simply-supported } \\
\text { square beam }\end{array}$ & $\begin{array}{l}\text { Deflection due to } \\
\text { concentrated force } \\
\text { at midspan, solid } \\
\text { cross section }\end{array}$ & Yes & $\begin{array}{l}\text { Beam Analytical } \\
\text { SAP2000 beam } \\
\text { Ansys Solid }\end{array}$ & $\begin{array}{l}\text { Good agreement } \\
\text { with analytical, } \\
\text { SAP2000, Ansys }\end{array}$ \\
\hline $\begin{array}{l}\text { 1B. Concentrated } \\
\text { force beam bending }\end{array}$ & $\begin{array}{l}\text { Simply-supported } \\
\text { hollow square } \\
\text { beam }\end{array}$ & $\begin{array}{l}\text { Deflection due to } \\
\text { concentrated force } \\
\text { at midspan, hollow } \\
\text { cross section }\end{array}$ & Yes & $\begin{array}{l}\text { Beam Analytical } \\
\text { SAP2000 beam } \\
\text { Ansys Solid }\end{array}$ & $\begin{array}{l}\text { Good agreement } \\
\text { with analytical, } \\
\text { SAP2000, Ansys }\end{array}$ \\
\hline $\begin{array}{l}\text { 2A. Distributed load } \\
\text { beam bending }\end{array}$ & $\begin{array}{l}\text { Simply-supported } \\
\text { square beam }\end{array}$ & $\begin{array}{l}\text { Deflection due to } \\
\text { uniform pressure } \\
\text { load along span, } \\
\text { solid cross section }\end{array}$ & Yes & $\begin{array}{l}\text { Beam Analytical } \\
\text { SAP2000 beam } \\
\text { Ansys Solid }\end{array}$ & $\begin{array}{l}\text { Good agreement } \\
\text { with analytical, } \\
\text { SAP2000, Ansys }\end{array}$ \\
\hline $\begin{array}{l}\text { 2B. Distributed load } \\
\text { beam bending }\end{array}$ & $\begin{array}{l}\text { Simply-supported } \\
\text { hollow square } \\
\text { beam }\end{array}$ & $\begin{array}{l}\text { Deflection due to } \\
\text { uniform pressure } \\
\text { load along span }\end{array}$ & Yes & $\begin{array}{l}\text { Beam Analytical } \\
\text { SAP2000 beam } \\
\text { Ansys Solid }\end{array}$ & $\begin{array}{l}\text { Good agreement } \\
\text { with analytical, } \\
\text { SAP2000, Ansys }\end{array}$ \\
\hline 3. Simple Beam Hex & $\begin{array}{l}\text { Simply-supported } \\
\text { beam, hex duct } \\
\text { cross section }\end{array}$ & $\begin{array}{l}\text { Deflection due to } \\
\text { uniform pressure } \\
\text { load along span }\end{array}$ & Yes & $\begin{array}{l}\text { Beam Analytical } \\
\text { SAP2000 beam } \\
\text { Ansys Solid }\end{array}$ & $\begin{array}{l}\text { Good agreement } \\
\text { with, SAP2000, } \\
\text { Ansys }\end{array}$ \\
\hline $\begin{array}{l}\text { 4. Concentrated force } \\
\text { beam bending }\end{array}$ & $\begin{array}{l}\text { Fixed-end, } \\
\text { cantilever square } \\
\text { beam }\end{array}$ & $\begin{array}{l}\text { Deflection due to } \\
\text { concentrated force } \\
\text { at the free end }\end{array}$ & Yes & $\begin{array}{l}\text { Beam Analytical } \\
\text { SAP2000 beam } \\
\text { Ansys Solid }\end{array}$ & $\begin{array}{l}\text { Good agreement } \\
\text { with analytical, } \\
\text { SAP2000, Ansys }\end{array}$ \\
\hline $\begin{array}{l}\text { 5. IAEA Verification } \\
\text { Problem } 1\end{array}$ & $\begin{array}{l}\text { Fixed-end } \\
\text { cantilever, with } \\
\text { prescribed thermal } \\
\text { gradient, hex duct }\end{array}$ & $\begin{array}{l}\text { Deflection due to } \\
\text { differential thermal } \\
\text { expansion induced } \\
\text { by thermal gradient }\end{array}$ & Yes & $\begin{array}{l}\text { Ansys Solid } \\
\text { IAEA VP1 }\end{array}$ & $\begin{array}{l}\text { Good agreement } \\
\text { with analytical } \\
\text { and Ansys }\end{array}$ \\
\hline
\end{tabular}




\begin{tabular}{|c|c|c|c|c|c|}
\hline Problem & Description & Physics & $\begin{array}{l}\text { MOOSE Run } \\
\text { Completed? }\end{array}$ & $\begin{array}{l}\text { Code or Analytical } \\
\text { Comparison }\end{array}$ & Results \\
\hline $\begin{array}{l}\text { 6. IAEA Verification } \\
\text { Problem 3A }\end{array}$ & $\begin{array}{l}\text { Fixed-end } \\
\text { cantilever ducts } \\
\text { with prescribed } \\
\text { thermal gradient. } \\
\text { Single duct } \\
\text { bowing into } \\
\text { cluster of ducts } \\
\text { (symmetry) }\end{array}$ & $\begin{array}{l}\text { Deflection due to } \\
\text { the differential } \\
\text { thermal expansion } \\
\text { induced by thermal } \\
\text { gradient. Contact } \\
\text { interaction } \\
\text { between the cluster } \\
\text { of ducts }\end{array}$ & Preliminary & $\begin{array}{l}\text { IAEA VP3A results } \\
\text { Ansys }\end{array}$ & $\begin{array}{l}\text { Results are still } \\
\text { being fine-tuned } \\
\text { for comparison } \\
\text { between IAEA } \\
\text { and Ansys } \\
\text { results }\end{array}$ \\
\hline
\end{tabular}




\section{Future Examples}

The current assessment focused on single duct deformation responses, but to determine the capabilities of MOOSE for full reactor problems, interactions between ducts need to be modeled through contact. Assessment is needed on the capabilities of the current contact algorithms and how they can be applicable to larger core deformation problems, and whether any additional work will be required to improve the contact detection. Additional examples including irradiation effects (swelling and creep) are also needed. The follow subsections will describe some of the future examples planned.

\subsection{Cluster of Ducts}

The following examples consider multiple duct contact through a small cluster of the indicated ducts. These examples have been developed as part of the IAEA examples, with code-to-code results for comparison.

\subsubsection{IAEA Verification Problem 3B}

This example examines the behavior of a single duct thermally bowing into a $120^{\circ}$ symmetric sector of a core with free boundaries around the symmetric lines (Figure 3.1). The dashed red lines indicate the location of the free boundary, and the blue arrow indicates the direction of the thermal bow, flat to flat along the duct cross section. The desired outputs are the interactions between ducts at the ACLP and TLP contact locations. 


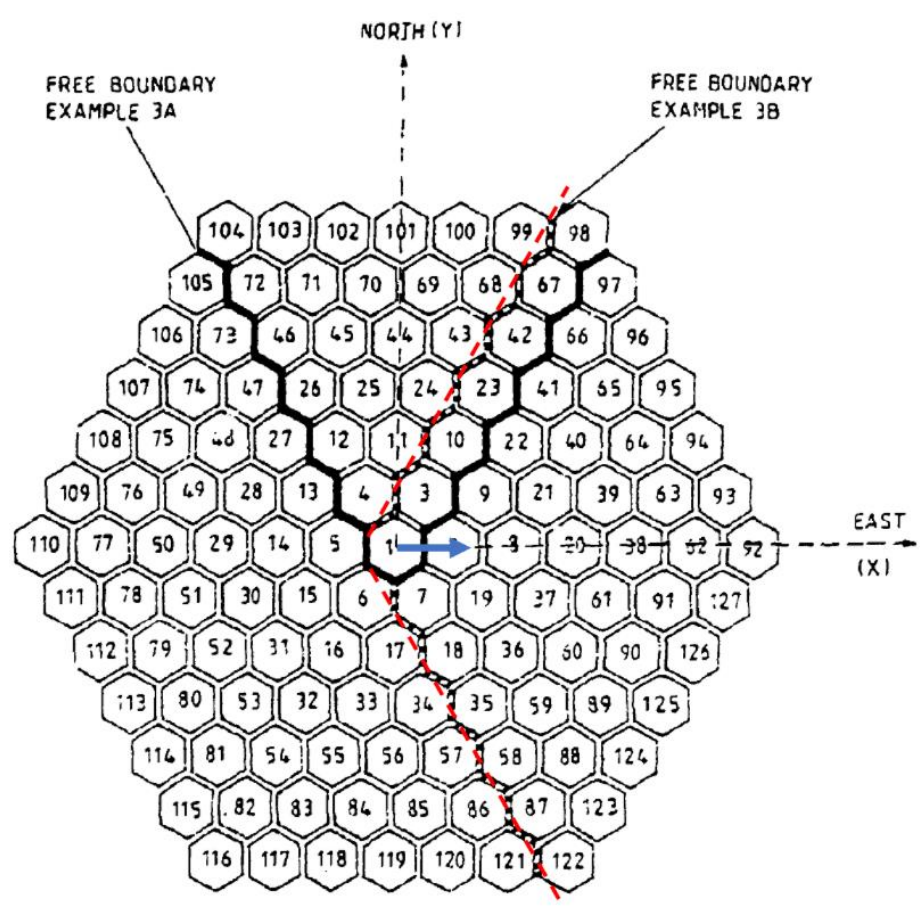

Figure 3.1. Model for IAEA VP3B of $120^{\circ}$ symmetric core region with a free boundary, represented by the red dashed line. The blue arrow indicates the direction of the thermal gradient induced bow for duct 1 (Adapted from [4] (C IAEA).

\subsection{Core Symmetric Sector}

\subsubsection{IAEA Verification Problem 4}

This example examines the behavior of a $30^{\circ}$ symmetric core region with an outward temperature gradient applied to row 5 of the core. The temperature gradient of IAEA Verification Problem 1 is used but in the directions shown in Figure 3.2. The core and numbering are the same as in IAEA Verification Problem 3 but with the addition of a restraint ring with a clearance equal to the clearance between assembly load pads $(0.5 \mathrm{~mm})$. The desired outputs are the interactions between ducts at the ACLP and TLP contact locations. 


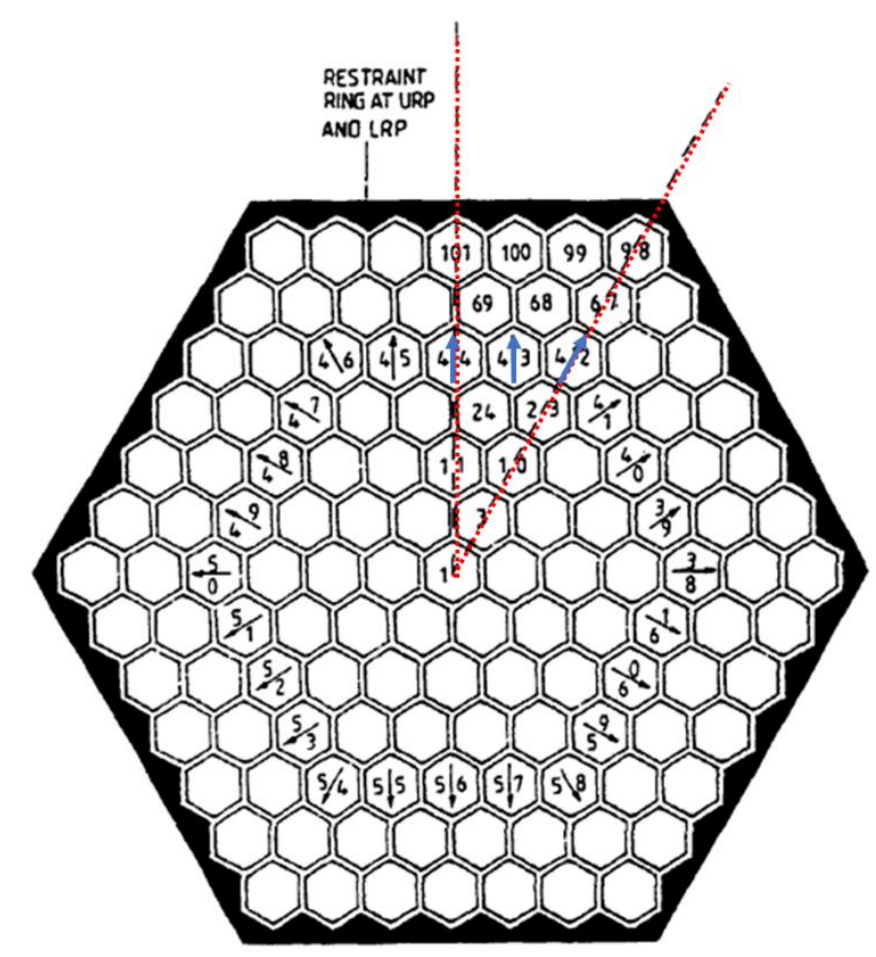

Figure 3.2. Model for IAEA VP4 of $30^{\circ}$ symmetric core region, represented by the red dashed line, with a core restraint ring at the TLP and ACLP. The blue arrows indicate the direction of the thermal gradient induced bow for ducts 42, 43, and 44 (Adapted from [4] () IAEA).

\subsection{Irradiation Effects}

\subsubsection{IAEA Verification Problem 5}

This example uses the same core restraint system and $30^{\circ}$ symmetric region as IAEA Verification Problem 4 but replaces the thermal bowing with irradiation swelling and creep behavior. The damage dose field, shown in Figure 3.3, decreases with radius until the circle noted in the figure. For this example, swelling is activated only on ducts 42,43 , and 44 (the same as for the thermal bowing). The desired outputs are the interactions between ducts at the ACLP and TLP contact locations for irradiation damage instead of thermal bowing behavior. 


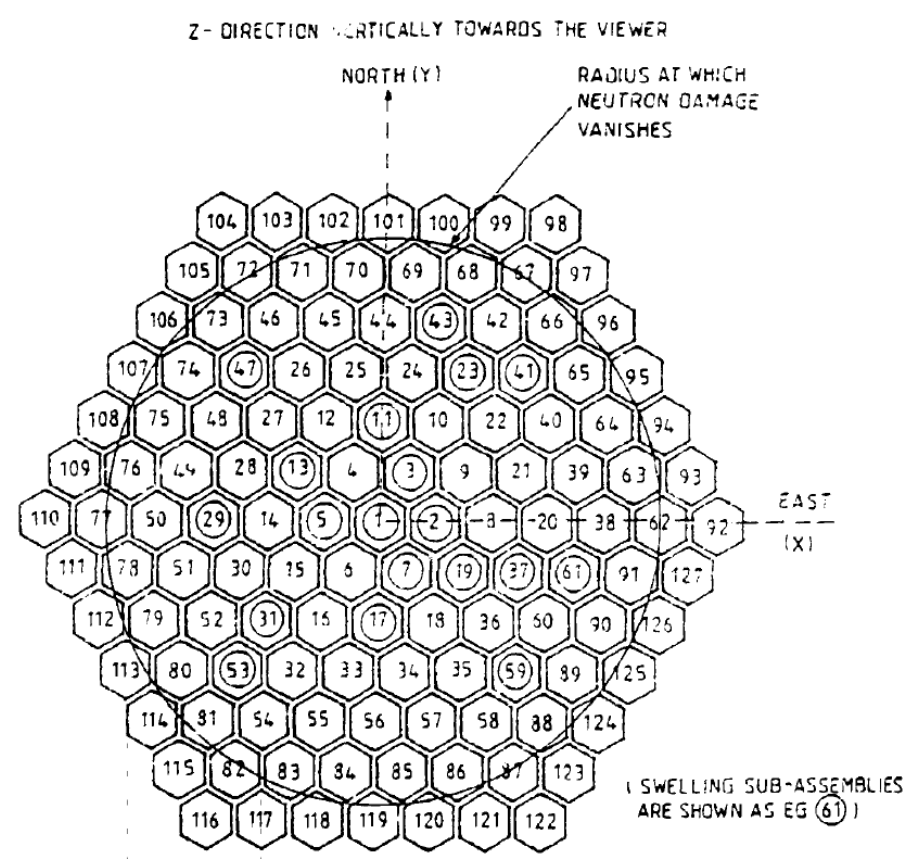

Figure 3.3. Core model showing the location where the neutron damage dose is active within the circle, for examples 5, 6, and 8A (Adopted from [4] (C) IAEA).

\subsubsection{IAEA Verification Problem 6}

This example examines the irradiation behavior of the entire 127 assembly core shown in Figure 3.3. It is identical to example 5 without the symmetry section.

\section{Multiphysics Collaboration Efforts}

Due to the many physics involved in modeling the complex phenomenon of radial core expansion, experts in several physics types are required. The authors of this report are actively collaborating with other researchers working on radial core expansion simulations. The initial stage of this assessment focuses solely on assessing the thermo mechanical response through MOOSE, but in parallel, researchers at Argonne National Laboratory, Idaho National Laboratory, and foreign agencies are engaged in thermal hydraulic, neutronics, and multiphysics research on this topic.

Specifically, thermal hydraulics studies are underway in the Computational Science Division at ANL to examine the impact of the thermal hydraulic model resolution on radial core expansion predictions in the presence of thermal feedback. Comparisons between subchannel, porous media, and turbulence-resolved Computational Fluid Dynamics (CFD) for a number of single-assembly geometries is being performed to understand the resolution needed to accurately predict the duct 
temperatures that drive the thermal expansion. Sensitivity studies will be performed to identify which closure models in the coarse-mesh industry-level analysis tools have the greatest impact on duct temperature predictions; this will guide subsequent high-resolution CFD calculations to generate more accurate coarse-mesh closure terms - such as an effective thermal conductivity that allows homogenized models to match bulk inter-assembly heat transfer rates.

Following these sensitivity studies, ANL will conduct high-resolution full core multiphysics calculations for various sodium fast reactor systems using NekRS CFD, OpenMC Monte Carlo transport, and the MOOSE tensor mechanics module. This multiphysics coupling will be the first fully coupled software application that implicitly models the combined effects of thermalhydraulics, neutron transport, and solid mechanics with on-the-fly deforming geometries. The assessment described in this report is an important first step to ensuring that the MOOSE tensor mechanics module is capable of providing the solid mechanics feedback to this coupled code system for fast reactor applications.

Studies performed by INL, ANL, and the NRC on modeling radial core expansion physics are also being shared for awareness. Separately, the authors are part of the Civil Nuclear Working Group US-Japan Bilateral for radial core expansion whereby ideas for verification, validation, and code development are exchanged on a regular basis.

\section{Summary}

This report summarizes the assessment done to date of the MOOSE Tensor Mechanics module to compute the structural mechanical response in radial core expansion problems. It is critically important to correctly predict the deformations of reactor core ducts in order to estimate the bowed shape and the effect on radial core expansion to reactivity. Several example problems have been formulated or taken from other literature (IAEA verification problems) to systematically test the needed capabilities. Through the examples presented, the Tensor Mechanics module can calculate the deformations with a high degree of accuracy when compared to analytical solutions for beam bending problems as well as compared to other 3D finite element software such as Ansys. Further assessment will focus on contact between ducts to correctly predict the deformation due to interactions between duct assemblies within the core, as well as irradiation effects on the materials (irradiation swelling and creep). 


\section{Acknowledgments}

This work was funded by the DOE-NE Advanced Modeling and Simulation program (DOE_NEAMS) under the Application Drivers Technical Area. This work used divisional cluster computing resources hosted at Argonne National Laboratory.

The authors would like to thank April Novak (Argonne National Laboratory) for reviewing this document and providing consultation on various aspects of the simulations and path forward for radial core expansion modeling.

\section{References}

[1] N. Wozniak, E. Shemon, and J. Grudzinski, "Review of Tools for Modeling Core Radial Expansion in Liquid Metal-Cooled Fast Reactors," ANL/NSE-20/41, 1755931, 164547, Nov. 2020. doi: 10.2172/1755931.

[2] “MOOSE Framework.” https://www.mooseframework.org/ (accessed Jul. 23, 2020).

[3] F. P. Beer, E. R. Johnston, J. T. DeWolf, and D. F. Mazurek, Mechanics of Materials, 6th ed. New York: McGraw-Hill, 2012.

[4] "Verification and Validation of LMFBR Static Core Mechanics Codes Part I," International Atomic Energy Agency, Vienna, IWGFR/75, 1990. 


\section{Argonne}

Nuclear Science and Engineering Division

Argonne National Laboratory

9700 South Cass Avenue

Argonne, IL 60439

www.anl.gov

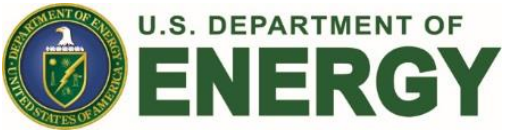

Argonne National Laboratory is a U.S. Department of Energy laboratory managed by UChicago Argonne, LLC 